


\title{
It Takes a Village: The Economics of Parenting with Neighborhood and Peer Effects*
}

\author{
Francesco Agostinelli Matthias Doepke \\ Giuseppe Sorrenti Fabrizio Zilibotti
}

April 2020

\begin{abstract}
As children reach adolescence, peer interactions become increasingly central to their development, whereas the direct influence of parents wanes. Nevertheless, parents may continue to exert leverage by shaping their children's peer groups. We study interactions of parenting style and peer effects in a model where children's skill accumulation depends on both parental inputs and peers, and where parents can affect the peer group by restricting who their children can interact with. We estimate the model and show that it can capture empirical patterns regarding the interaction of peer characteristics, parental behavior, and skill accumulation among US high school students. We use the estimated model for policy simulations. We find that interventions (e.g., busing) that move children to a more favorable neighborhood have large effects but lose impact when they are scaled up because parents' equilibrium responses push against successful integration with the new peer group.
\end{abstract}

*We thank Matt Wiswall, participants at the "Economics of Child Development" conference at the University of Chicago, and seminar participants at Banco Central de Chile, Northwestern University, Penn State University, Temple University, Universidad de Chile, University of British Columbia (Woodward Lecture), and Yale University for helpful suggestions that greatly improved the paper. Financial support from the SNSF (grant 100018-165616) and NSF (grant SES-1949228) during the preparation and execution of the project are gratefully acknowledged. Agostinelli: Department of Economics, University of Pennsylvania, $133 \mathrm{~S} 36^{\text {th }}$ St, Philadelphia, PA 19104 (email: fagostin@sas.upenn.edu). Doepke: Department of Economics, Northwestern University, 2211 Campus Drive, Evanston, IL 60208 (email: doepke@northwestern.edu). Sorrenti: Amsterdam School of Economics, University of Amsterdam, Roetersstraat 11, Amsterdam, 1018 WB (email: g.sorrenti@uva.nl). Zilibotti: Department of Economics, Yale University, 28 Hillhouse Avenue, New Haven, CT 06520 (email: fabrizio.zilibotti@yale.edu). 


\section{Introduction}

The two most important influences on children's development are their parents and their peers. The importance of these two factors evolves as children grow up: once children pass into adolescence, parents' ability to hold sway over them wanes, whereas the influence of peers looms larger. Yet, parents can try to influence how their adolescent children select their peers. They can choose neighborhoods and schools, and coax their children into activities and hobbies that expose them to a favorable peer group. Or, more directly, they can push their children to associate with or stay away from specific peers.

In this paper, we examine the determinants and consequences of parental decisions that are aimed at shaping their children's peer groups. We build on evidence from the Add Health study, which follows a large group of children in the United States throughout the high school years. The data set includes information on children's grades, test scores, and socio-economic characteristics of their families. Crucially for our purposes, it also provides rich information on parents' behavior and on children's friendship networks. We are specifically interested in how parents intervene in peer-group formation. The data set includes a question that addresses this issue directly: "Do your parents let you make your own decisions about the people you hang around with?" We classify a parent whose child answers "No" as adopting an authoritarian parenting style about friendsor more simply, as authoritarian. ${ }^{1}$ Conversely, when the child answer "Yes," a parent is classified as adopting a nonauthoritarian style.

The first question we address is whether parents' choice between the authoritarian versus nonauthoritarian style can be understood from the perspective of a rational-choice theory of parenting, where parents are concerned about their children's present and future welfare and are responsive to the characteristics of both

\footnotetext{
${ }^{1}$ Of course, the notion of an authoritarian parenting style (stretching back to Baumrind 1967) is usually more general and covers many aspects of behavior; we use the shorthand "authoritarian" because we are specifically interested in parents' impact on peer selection. In the developmental psychology literature, the notion of authoritarian parenting style often carries a negative connotation and is associated with unfavorable outcomes (see, e.g., Brooks 2013). In contrast, following Doepke and Zilibotti (2017), we do not attach a value judgement to the use of authoritarian parenting, and simply use "authoritarian" to denote parents who restrict their children's choices.
} 
their children and the surrounding community. We begin answering this question by documenting correlations between the parenting style parents adopt and the peer environment their children face. We find that parents are more likely to be authoritarian (i.e., meddle in their children's peer choices) when the average quality of the peer group (measured by grades) is low and when its variance is high. Informally speaking, parents are more authoritarian when their children are exposed to the influence of "bad apples." Authoritarian parenting also appears to be effective: intervening in a child's peer formation is associated with an improvement over time in the quality of a child's set of friends.

These correlations are consistent with the view that parents' actions are a purposeful response to the environment that their children face. To study the implications of this hypothesis more formally, we develop a model that combines dynamic skill acquisition by children (Cunha and Heckman 2007) with endogenous formation of friendship networks (Agostinelli 2018) and a rational-choice theory of parent-child interactions. In the model, building on Doepke, Sorrenti, and Zilibotti (2019), parents' concern for their children has a paternalistic component: parents place relatively more weight on the children's accumulation of skills than do the children themselves. This motivates interventions aimed at fostering skills. Parental interventions can take two forms. First, parallel to what we observe in the Add Health data, parents can adopt an authoritarian parenting style to influence their child's selection of friends. Second, parents can invest time to directly support their children's skill formation, such as helping them with homework or motivating them to work hard. We interpret such time investments as an element of an authoritative parenting style. ${ }^{2}$ The two strategies are not exclusive: parents may decide to combine elements of authoritarian and authoritative parenting.

Children form friendships based on the mutual agreement of two potential friends, where the utility a child derives from a friendship depends on their own and the friend's characteristics as well as on match-specific shocks. Authoritarian parent-

\footnotetext{
${ }^{2}$ Authoritative parenting is generally characterized by high parental engagement and by explaining the reasoning behind parents' views rather than just demanding obedience as in the authoritarian style. See Doepke and Zilibotti (2019) for a detailed discussion of parenting styles from an economic perspective.
} 
ing lowers the utility a child earns from befriending lower-skill peers, which captures the effect of parental disapproval. If successful, this intervention improves the quality of a child's peer group, which in turn feeds back into the child's own accumulation of skills. However, in line with the child development literature, authoritarian parenting has some negative repercussions. Meddling in the choice of friends puts a strain on the parent-child relationship, making the child less receptive to other parental interventions.

These opposing effects yield a tradeoff for parents between improving the selection of peers and the collateral damage caused by parental interference. The resolution of this tradeoff hinges on the peer environment a child is exposed to. Influencing the choice of friends is more urgent in riskier neighborhoods where certain social interactions could lure children into hazardous behavior. In contrast, in homogeneous neighborhoods where most potential peers have a solid family background, parents can grant their children leeway and spare them the downsides of an authoritarian upbringing.

We estimate the model to match a set of data moments and find that it provides a good fit for the empirical relationships between child skills, peers skills, and parenting style observed in the Add Health study. The primary source of identification in the estimation is the within-school and within-grade variation in the makeup of the potential peer group. Even so, the model provides a good fit for the observed variation in parenting styles across schools from richer and poorer neighborhoods, which is not directly targeted.

The estimated model implies a flexible interaction between different dimensions of parenting style. For nonauthoritarian parents, authoritative investments in a child's skills are a substitute input for the quality of the child's peers (in line with Agostinelli 2018). As a result, parents increase their time investment when their children face a worse peer group. In contrast, the time investment of authoritarian parents does not respond to the quality of peers. These findings suggest that parents regard authoritative time investments and authoritarian restrictions on the choice of friends as alternative strategies for responding to a problematic peer environment.

Having confirmed that parenting choices can indeed be understood as a rational 
response to incentives arising from a child's environment, we move on to a second question: What are the implications of endogenous parenting for the effects of policy interventions that are also aimed at shaping peer effects?

We focus specifically on a busing policy that moves children from a low-quality school (measured by average test scores) to a better one. Our model implies that bused children face two barriers to integration. The first is homophily bias in children's preferences, i.e., the tendency for children to associate with peers who are similar to themselves. The second is the endogenous response of parents in the host neighborhood. We find that the strength of these barriers hinges on the scale of the intervention. A small-scale policy that moves only a few children has large beneficial effects on the moved children and hardly any negative impact on the children already at the receiving school. However, for two reasons, the effectiveness of the policy declines sharply as it is scaled up to cover more children. First, if only few children are bused, they have no choice other than to mingle with the children in the new school. In contrast, when the policy is scaled up, homophily bias induces the bused children to increasingly stick together and mix less with others. Second, as more children are bused, parents at the receiving school increasingly turn authoritarian to prevent their own children from befriending the new arrivals. In other words, parents' equilibrium responses push against successful integration.

Beyond busing, other examples of policies where similar effects may arise include school choice policies and tracking policies within schools. We also study counterfactual policies that alter the peer environment for all children by reducing initial inequality in skills either within or across neighborhoods. Reducing initial inequality across the board or within neighborhoods (e.g., through policies targeting early child development) generally has beneficial effects on the accumulation of skills, in significant part because lower inequality reduces the use of authoritarian parenting. Results are less favorable for a policy that reduces inequality across neighborhoods, for instance by removing all residential segregation so that the composition of all neighborhoods turns identical, while holding constant overall inequality. In our model, this policy has a negative average effect on skill accumulation because inequality increases within most 
neighborhoods, which due to homophily bias and the defensive response of parents, increases barriers against the successful integration of children from different backgrounds. All these findings underline the importance of taking parental responses into account when considering the effects of policies that are aimed at shaping peer effects.

\section{Relationship to Literature}

This paper links three strands of the recent literature on the determinants of child development. The first is the literature on children's skill formation, including James Heckman's recent work with different coauthors (e.g., Cunha and Heckman 2007; Cunha, Heckman, and Schennach 2010), which has led to new insights on how children's skills and attitudes evolve as a function of endowments and parental and other inputs. ${ }^{3}$ We build on this literature in our modeling of children's skill acquisition, and also introduce new elements, such as alternative investment strategies (parenting styles), through which parents can foster their children's skills.

The second strand of literature is the growing body of multidisciplinary research studying the importance of neighborhood effects for human capital formation and inequality of opportunity. ${ }^{4}$ This literature shows that children who grow up in distressed areas tend to reach lower outcomes and display less upward mobility when compared to children from wealthier areas (e.g., Cutler and Glaeser 1997; Chetty et al. 2014). In a recent study, Chetty, Hendren, and Katz (2016) argue that moving to a less poor area improves long-term outcomes for children who move at a young age. The importance of childhood exposure to neighborhoods is also supported by recent papers studying tax records of millions of US families moving across different areas (Chetty and Hendren 2018a, 2018b) and

\footnotetext{
${ }^{3}$ Other important studies in this literature include Todd and Wolpin (2003), Heckman, Stixrud, and Urzua (2006), Todd and Wolpin (2007), Cunha and Heckman (2008), Almlund et al. (2011), Dahl and Lochner (2012), Løken, Mogstad, and Wiswall (2012), Heckman, Pinto, and Savelyev (2013), Del Boca, Flinn, and Wiswall (2014), Agostinelli and Wiswall (2016), Agostinelli and Sorrenti (2018), Attanasio, Meghir, and Nix (2019), and Attanasio et al. (2020). For literature reviews, see Heckman and Mosso (2014) and Attanasio (2015).

${ }^{4}$ See Jencks and Mayer (1990), Sampson, Morenoff, and Gannon-Rowley (2002) and Durlauf (2004) for early reviews.
} 
the findings of Chyn (2018) on the effects of a program of public housing demolitions in Chicago that forced poor families to relocate to less disadvantaged areas.

These empirical studies leave open the question through which mechanism the benefits of exposure to better neighborhood arise. In addressing this question, our study complements the theoretical literature on social interactions within neighborhoods (e.g., Brock and Durlauf 2001a; Brock and Durlauf 2001b ; Brock and Durlauf 2002; Durlauf and Ioannides 2010) and the empirical literature on peer effects in education. ${ }^{5}$ Calvó-Armengol, Patacchini, and Zenou (2009) estimate a friendship network model using, as we do, the Add Health data. Their main finding is that a child's position in the network, as measured by its Bonacich centrality, has an impact on school performance. ${ }^{6}$ A recent study by List, Momeni, and Zenou (2019) documents large spillover effects of programs targeting disadvantaged children on the cognitive and noncognitive skills of other local children. In line with our modeling approach, the evidence suggests that these spillovers operate through children's social networks. Angrist and Lang (2004) study the effect of a desegregation busing policy in the Boston area. They find that negative spillovers on the receiving community are small, although there are some negative effects on local black children who are more likely to interact with the bused children. These results are consistent with the findings of our counterfactual policy analysis. Two recent macroeconomic papers by Eckert and Kleineberg (2019) and Fogli and Guerrieri (2018) study the effect of neighborhood choice on human capital accumulation and social mobility. We do not explicitly model the choice of neighborhood, but unlike these studies, we provide a microfoundation for peer effects and the process of friendship formation, and we allow for direct parental interventions in children's peer group formation.

\footnotetext{
${ }^{5}$ Case and Katz (1991) is an early contribution on the effect of neighborhood peers on the behaviors of youths. Papers estimating peer effects in education under a variety of identification strategies include Hoxby (2000), Sacerdote (2001), Zimmerman (2003), Sacerdote (2011), Arcidiacono et al. (2012), Carrell, Sacerdote, and West (2013), Tamayo Castano (2016), and Feld and Zölitz (2017). Altonji and Mansfield (2018) address econometric issues in the estimation of group treatment effects in the presence of selection effects. Blume et al. (2011) and Blume et al. (2015) provide an overview of the identification of various social interactions models.

${ }^{6}$ Other studies on peer effects using the Add Health data set include Bifulco, Fletcher, and Ross (2011), Badev (2016), Mele (2019), and Olivetti, Patacchini, and Zenou (2020).
} 
The third related strand of literature consists of recent work on the economics of parenting that merges insights from the developmental psychology literature with the Beckerian tradition of family economics, including Doepke and Zilibotti (2017), Doepke and Zilibotti (2019), and Doepke, Sorrenti, and Zilibotti (2019). While the psychology literature (following Baumrind 1967) regards parenting styles as given traits of parents, the economics literature treats them as the endogenous choice of rational parents who seek to influence the behavior of their children, with whom they disagree on occasion. ${ }^{7}$ Strategic interaction between parents and children is also central to Del Boca et al. (2019), who focus on monetary incentives that parents provide for their children (related to Weinberg 2001) rather than on interference with friend selection. Relative to this literature, the key innovation of this paper is to consider how parenting choices interact with peer effects. ${ }^{8}$ In terms of modeling peer interactions, we build on Agostinelli (2018), who estimates a dynamic model of skill formation where children choose their own peer groups. ${ }^{9}$ However, in his setting, parents do not choose a parenting style or interfere in their children's peer selection, which is the main focus of our study.

In the following section, we describe the data and provide descriptive evidence. In Section 3, we develop a structural model of parent-child interactions with peer effects. Section 4 describes the model estimation. Section 5 uses the model for policy analysis, and Section 6 concludes. The appendix contains additional empirical results, details on the measurement of skills and parenting styles, and

\footnotetext{
${ }^{7}$ Earlier work on the economics of parenting includes Akabayashi (2006) and Lizzeri and Siniscalchi (2008), who emphasize informational frictions and learning. More recently, Kim (2019) models the role of parental punishment as a parent-child communication channel. Other empirical studies on different dimensions of parenting include, among others, Patacchini and Zenou (2011), Zumbuehl, Dohmen, and Pfann (2018), Brenøe and Epper (2019), and Cobb-Clark, Salamanca, and Zhu (2019).

${ }^{8}$ The link between parenting and peer effects has been stressed previously in the developmental psychology literature. For instance, Brooks (2013) describes parenting as a "process of action and interaction between parent and child .... Society is a third dynamic force in the process. ... The child, the parent, and society all influence the process of parenting, and, in turn, are changed by it" (pp. 6-7). The impact of parents through shaping their children's peer environment is acknowledged even by authors who are skeptical of the influence of parents on adolescent children, such as Harris (1998) .

${ }^{9}$ A contemporaneous nonstructural paper by Özdemir (2019) also uses the Add Health data to study the response of parents to the environment, with a special focus on the differential effects of time investments of mothers and fathers.
} 
robustness exercises.

\section{Parenting, Peers, and Skills in the Add Health Data}

In this section, we describe the data and document empirical correlations between skill accumulation, peers, and parental interventions that motivate our structural theory.

\subsection{Data}

The National Longitudinal Study of Adolescent to Adult Health (Add Health) is a nationally representative longitudinal survey of adolescents in the United States. The original data set includes about 90,000 students from 132 schools in the school year 1994-95. Students are in grades 7-12. Our analysis focuses on the baseline survey (Wave I) and the 1996 follow up (Wave II).

A subsample of students is selected for a home interview that includes questionnaires for both the students and their parents. The data set includes detailed information on family background, grades, and test scores. The survey asks questions that can be used for measuring parenting styles. Importantly for our research, the survey also asks detailed questions on students' peers. Each student is asked to nominate their best five male and best five female friends. Since students are observed repeatedly, we have information on how peer groups evolve over time. In addition, we can study how students' characteristics (including grades and tests scores) affect peer group formation.

We are interested in children's answers to the question: "Do your parents let you make your own decisions about the people you hang around with?" We consider a parent whose child answers "No" as behaving in an authoritarian fashion about friends. We classify such parents as authoritarian; all others are nonauthoritarian. The authoritarian group comprises 13 percent of parents in the sample we use in our analysis. We also construct a measure of parental investment based on activities parents do together with their children, such as working on a project for school, talking about a party the child attended, or talking about a personal 
problem. ${ }^{10}$ We consider parental investments of this kind as an element of an authoritative parenting style. The data set does not provide information on monetary investments in child-rearing activities.

Appendix Table A-1 provides the summary statistics of our main variables. Appendix $B$ provides additional information on how we measure skills and parental investments.

\subsection{Authoritarian Parenting Across Schools}

In this section, we provide some descriptive evidence. Our main hypothesis is that parenting behavior is driven by parents' concern about children's skill formation. Therefore, we expect parents to be more authoritarian when their children are exposed to peers who may disrupt human capital accumulation. The data supports this conjecture.

Figure 1: Authoritarian Parenting and Neighborhood Characteristics
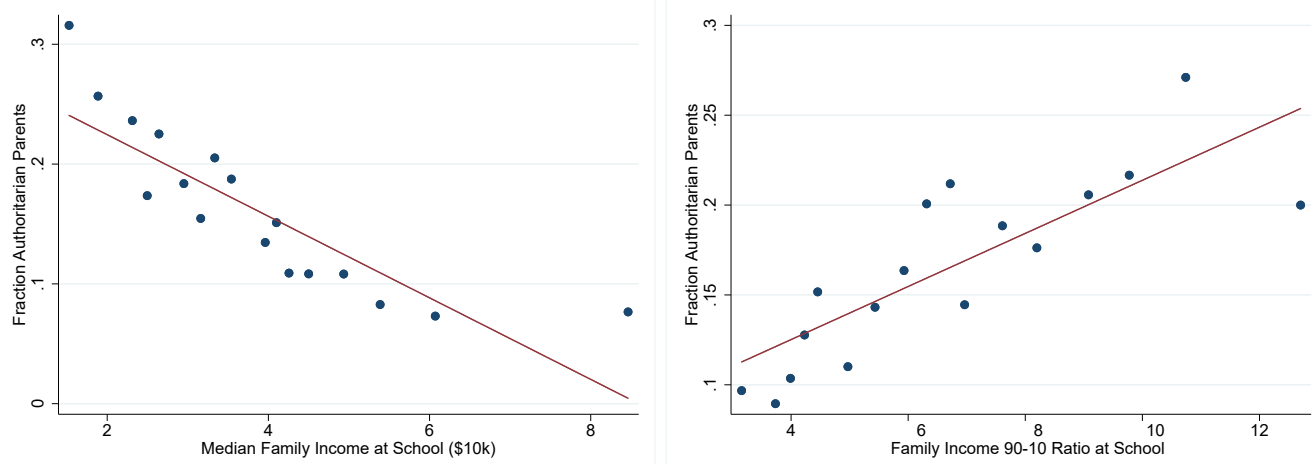

The figure shows how the incidence of the authoritarian parenting style varies with withinschool average family income (left panel) and inequality (right panel). Inequality is measured by the 90th-10th percentile ratio of within-school family income.

Figure 1 shows how authoritarian parenting varies across schools with different characteristics. The left panel displays a binned scatter plot of the relationship between median family income and the fraction of authoritarian parents at the school level, whereas the right panel shows the relationship between income inequality and authoritarian parenting. The figure shows that across schools, the

\footnotetext{
${ }^{10}$ See Appendix Table A-1. We restrict attention to activities done by the child with its mother to avoid selection problems, since the father is often not present.
} 
Table 1: Authoritarian Parenting and Peer Environment Across Schools

Authoritarian

(1)

\begin{tabular}{lcc}
\hline Median Family Income & $-0.033^{* * *}$ & $-0.021^{* * *}$ \\
at School & $(0.005)$ & $(0.004)$ \\
& & \\
90-10 Family Income & $0.006^{*}$ & $0.005^{*}$ \\
at School & $(0.003)$ & $(0.003)$ \\
\hline Mean Dep & 0.154 & 0.154 \\
Obs & 15064 & 15064 \\
Clusters & 114 & 114 \\
Controls & No & Yes \\
\hline \hline
\end{tabular}

The table shows the estimated coefficients of regressions whose dependent variable is an indicator variable for authoritarian parenting at the individual level. The regressions include mother's education, family income, child's race, age, and gender as control variables. Standard errors are clustered at the school level.

proportion of parents adopting the authoritarian parenting style is decreasing with the median income and increasing with income inequality. Broadly speaking, parents are more likely to meddle in the choice of friends when there are more children from disadvantaged families present. The differences are quantitatively large. Moving from a neighborhood (school) with a median income of $\$ 20,000$ to one with a median income of $\$ 60,000$ or more decreases the percentage of parents behaving in an authoritarian fashion from 26 percent to 8 percent. Likewise, moving from the three most equal to the three most unequal bins is associated with more than doubling the share of authoritarian parents. The same pattern emerges in multiple regressions where we simultaneously include median income and income inequality and control for parental characteristics, as shown in Table 1.

While our definition of authoritarian parenting focuses on parental intervention in peer formation, the patterns documented above are robust to other ways of 
Table 2: Authoritarian Parenting and Peer Environment within Schools

\begin{tabular}{|c|c|c|c|c|c|c|}
\hline & \multicolumn{6}{|c|}{ Authoritarian } \\
\hline & $(1)$ & $(2)$ & (3) & $(4)$ & (5) & (6) \\
\hline \multirow[t]{2}{*}{ Mean GPA within Grade } & $-0.114^{* *}$ & & -0.064 & -0.059 & & -0.036 \\
\hline & $(0.046)$ & & $(0.047)$ & $(0.042)$ & & $(0.043)$ \\
\hline \multirow[t]{2}{*}{ SD GPA within Grade } & & $0.329^{* * *}$ & $0.269^{* * *}$ & & $0.206^{* *}$ & $0.181^{* *}$ \\
\hline & & $(0.087)$ & $(0.087)$ & & $(0.087)$ & $(0.089)$ \\
\hline Mean Dep & 0.130 & 0.130 & 0.130 & 0.130 & 0.130 & 0.130 \\
\hline Obs & 10057 & 10057 & 10057 & 10057 & 10057 & 10057 \\
\hline Clusters & 63 & 63 & 63 & 63 & 63 & 63 \\
\hline Controls & No & No & No & Yes & Yes & Yes \\
\hline School F.E. & Yes & Yes & Yes & Yes & Yes & Yes \\
\hline
\end{tabular}

The table shows the estimated coefficients of regressions whose dependent variable is an indicator variable for authoritarian parenting at the individual level. The SD GPA grade is the standard deviation in GPA across pupils within school and grade. All regressions include school fixed effects, as well as mother's education, family income, and child's race, age, and gender as control variables. Standard errors are clustered at the school level.

measuring parenting style. In Appendix Figure A-1, we construct measures of parenting styles based on the values parents emphasize in child rearing, similar to Doepke and Zilibotti (2017). ${ }^{11}$ The figure shows that parents tend to be more permissive in wealthier and more equal neighborhoods, while they tend to be more authoritative and authoritarian in poorer and more unequal neighborhoods. This is consistent with the cross-country evidence documented by Doepke and Zilibotti (2017).

\footnotetext{
${ }^{11}$ We use the answer parents give to the following question: "Of the following, which do you think is the most important thing for a boy/girl to learn? Be well-behaved, work hard, think for himself, help others, be popular." We classify parents as authoritarian when they choose "be well-behaved," as authoritative when they choose "work hard," and as permissive when they choose "think for themselves." In the figure, we exclude parents who choose either "think for himself" or "be popular." The result does not change significantly if we classify the excluded parents as permissive.
} 


\subsection{Authoritarian Parenting Within Schools}

A natural concern is that the correlation might be driven by omitted variables at the neighborhood level. To address this concern, we consider within-school regressions exploiting variations across cohorts. We focus on the same measure of peer quality that we will use in our structural model below, namely, a student's grade point average (GPA). Table 2 shows the results of regressing parenting style (authoritarian) on the mean and standard deviation of GPA among the children in a given school cohort. Parents are significantly more inclined to be authoritarian when their children are exposed to peers with low and unequal skills (where inequality is measured by the standard deviation of GPA) even when controlling for school fixed effects and family characteristics. ${ }^{12}$ Remarkably, the correlation of parenting style with inequality in GPA is stronger and more robust than that of parenting style with the mean GPA. The range of variation for the standard deviation of GPA within grade is [0.47, 0.97]. Moving from the least to the most unequal cohort in the sample is associated with an increase of the incidence of the authoritarian parenting style between 9 (sixth column) and 16.5 (second column) percentage points. This is a large change, given that about 13 percent of parents in the sample are authoritarian in our sample.

The next question is whether authoritarian parenting makes a difference. To address this issue, we study the correlation between parenting style and the change in the quality of peers. In these regressions, we use information on each child's network of friends and test whether, conditional on the child's skill and on the average GPA of her friends, an authoritative parenting style is associated with a higher GPA of its peers in the following year. ${ }^{13}$ We control for school and grade fixed effects and exploit the variation across the realized set of friends for each child. Table 3 shows that in most cases the dummy for an authoritarian style has a positive coefficient. While the estimated coefficient is small and statistically insignificant in the entire sample, there is significant heterogeneity. In particular, the coefficient turns larger and highly significant when we zoom in on intact

\footnotetext{
${ }^{12}$ Appendix Table A-2 shows that the results are robust to using the Gini coefficient instead of the standard deviation as a measure of inequality.

${ }^{13}$ Note that we lose many observations because this regression requires that we observe both the GPA of the child and that of all her friends.
} 
Table 3: Authoritarian Parenting and Dynamics of Peer Quality

\begin{tabular}{|c|c|c|c|c|c|}
\hline & \multicolumn{5}{|c|}{ Next Period Peer GPA } \\
\hline & $(1)$ & $(2)$ & (3) & $(4)$ & (5) \\
\hline & \multirow[t]{2}{*}{ All } & \multirow[t]{2}{*}{ Intact Families } & \multicolumn{3}{|c|}{ Intact Families Only: } \\
\hline & & & $\begin{array}{l}\text { Low-Income } \\
\text { Neighborhood }\end{array}$ & $\begin{array}{l}\text { Medium-Income } \\
\text { Neighborhood }\end{array}$ & $\begin{array}{l}\text { High-Income } \\
\text { Neighborhood }\end{array}$ \\
\hline \multirow[t]{2}{*}{ Child's GPA } & $0.177^{* * *}$ & $0.251^{* * *}$ & $0.345^{* * *}$ & $0.226^{* * *}$ & $0.282^{*}$ \\
\hline & $(0.022)$ & $(0.030)$ & $(0.089)$ & $(0.023)$ & $(0.145)$ \\
\hline \multirow[t]{2}{*}{ Peer GPA } & $0.317^{* * *}$ & $0.297^{* * *}$ & 0.147 & $0.358^{* * *}$ & 0.179 \\
\hline & $(0.035)$ & $(0.065)$ & $(0.171)$ & $(0.052)$ & $(0.153)$ \\
\hline \multirow[t]{2}{*}{ Authoritarian } & 0.013 & $0.198^{* *}$ & $0.286^{*}$ & 0.107 & 0.212 \\
\hline & $(0.042)$ & $(0.081)$ & $(0.144)$ & $(0.077)$ & $(0.170)$ \\
\hline Obs & 1895 & 974 & 175 & 615 & 184 \\
\hline Clusters & 56 & 55 & 16 & 23 & 16 \\
\hline
\end{tabular}

The table shows the estimated coefficients of regressions whose dependent variable is the average GPA of peers in the second wave of interviews. The Peer GPA grade is the average GPA of peers in the first wave of interviews. All regressions include school-grade fixed effects, as well as mother's education, family income, and child's race, age, and gender as control variables. Standard errors are clustered at the school level.

families, i.e., families in which both parents are present. For these families, an authoritative parenting style is associated with a 0.20 average increase in the skills of future friends. The point estimate is even larger (0.29) in low-income neighborhoods where more parents are authoritarian. An intuitive interpretation for this heterogenous effect is that the parental intervention is magnified by the presence of two parents. While these regressions are suggestive, they are subject to important caveats related to selection issues. The costs and benefits of being authoritarian, both in terms of skill formation and potential psychological costs, may vary with the characteristics of children and the environment in a systematic and nonlinear way. We will show below with the aid of a structural model that a large causal effect of authoritative parenting is consistent with a small reduced-form regression coefficient.

Overall, the correlations described in this section suggest a rational motive for parents to interfere in the process of peer selection. To test this hypothesis more 
formally and to perform counterfactual policy analysis, we construct and estimate a structural model.

\section{A Model of Parents, Peers, and Skill Accumulation}

Consider an economy comprising a set of neighborhoods indexed by $n$, each populated by families composed of a child and a parent. The focal point of our analysis is the accumulation of children's skills $\theta_{i, t}$, where $i$ is the index of a child and $t$ denotes the time period. We model the interaction of parent and child from period $t=1$ to period $t=T$. In our empirical application this interval corresponds to the four years of high school (grades 9 to 12), so that $T=4$.

Figure 2: Model Timing

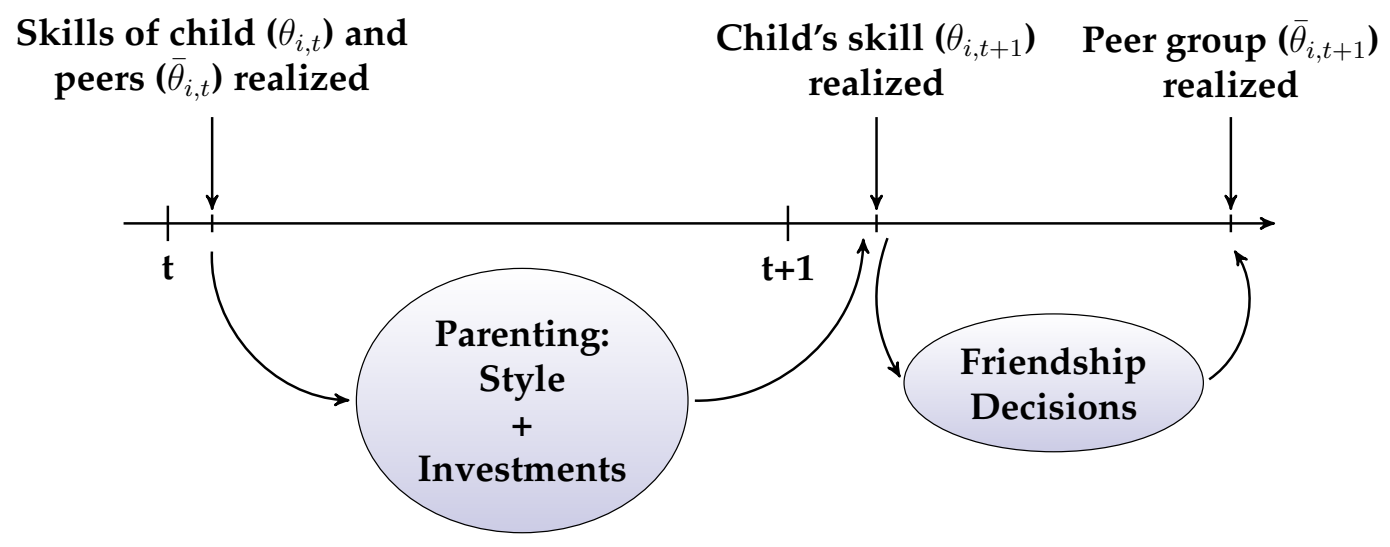

The figure shows the timeline of the model. The child's skills at $t=0$ are drawn from the initial distribution. The peers' skills at $t=0$ are determined by the peer environment (the distribution of children's skills at the school and grade level) and by the random utility preferences without parental interventions. From period $t=1$ onward, $\theta_{t}$ and $\bar{\theta}_{t}$ are endogenous state variables.

Each neighborhood $n$ is characterized by a set $\mathcal{X}^{n}$ of children living in the neighborhood and by the initial $(t=1)$ skill distribution of these children. All children living in a given neighborhood attend the same school. Figure 2 outlines the timing of events within each period. At the beginning of the period, the child's current skill level $\theta_{i, t}$ is realized. Next, the child forms friendships with some of the other children of the same age in the same school. The characteristics of these 
friends (which affect skill formation) are summarized by the variable $\bar{\theta}_{i, t}$. The parent can now make two choices that affect the evolution of the child's skills and peers. First, the parent can undertake (authoritative) parenting investments $I_{i, t}$ that affect the child's skill formation. Second, the parent chooses her parenting style, $P_{i, t} \in\{0,1\}$, where $P_{i, t}=1$ means that the parent behaves in an authoritarian fashion by interfering in the child's next round of friendship decisions. At the beginning of the next period, the child's updated skill $\theta_{i, t+1}$ is realized and the new group of friends with the average skill $\bar{\theta}_{i, t+1}$ is formed. These events are repeated until the final year of high school. Then, the child enters adult life with skills $\theta_{i, T+1}$.

\subsection{Preferences of Parents and Children}

The structure of preferences builds on Doepke and Zilibotti (2017) and Doepke, Sorrenti, and Zilibotti (2019). In particular, the utility of the parent combines elements of altruism and paternalism. Altruism means that the child's utility enters the parent's utility so that the parent wants the child to be "happy." In contrast, paternalism implies that the parent evaluates the child's choices and educational outcomes from her own standpoint. Specifically, the parent's paternalistic self attaches a higher weight on the child's skill accumulation than does the child herself. The conflicting motives of altruism and paternalism imply that the parent's behavior responds to the environment in a way that can be fitted to data. The paternalistic motive explains why the parent may want to interfere in the child's friendship decisions (against the child's wishes), and the altruistic motive explains why the parent will interfere only when the benefits of doing so are high relative to the child's loss of utility.

To keep the model parsimonious, we limit attention to the choices and state variables that are part of our empirical analysis and omit other factors such as goods consumption. In our notation, we employ the convention that lowercase variables correspond to the child and uppercase variables correspond to the parent. The individual state variables for a family are the child's skills $\theta_{i, t}$ and the characteristics of the child's peers $\bar{\theta}_{i, t}$. An additional aggregate state variable is the distribution of the children $\mathcal{X}^{n}$ in the neighborhood over skills at age $t$, which matters for friendship formation and peer effects. However, since in our analysis 
families do not switch neighborhoods, the aggregate state is taken as given by each family. ${ }^{14}$ Thus, our notation omits the aggregate state as an explicit state variable. Instead, we denote the dependence of utility and choices on neighborhood characteristics by indexing value functions by neighborhood $n$.

The parent decides on parenting style $\left(P_{i, t}\right.$ and $\left.I_{i, t}\right)$, and the child chooses peers, i.e., who to be friends with. We express the preferences of parent and child with value functions that summarize utility in a period after the child's current skills and peer group have already been realized so that the decisions concern the evolution of these variables into the next period.

The value function for child $i$ in neighborhood $n$ in period $t$ is given by:

$$
v_{t}^{n}\left(\theta_{i, t}, \bar{\theta}_{i, t}\right)=\max \left\{\mathrm{E}\left[u\left(\mathcal{F}_{i, t+1}\right) \mid \theta_{i, t}, \bar{\theta}_{i, t}\right]\right\} .
$$

Here $u\left(\mathcal{F}_{i, t+1}\right)$ captures the utility derived from peer interactions with the set of friends $\mathcal{F}_{i, t+1}$ chosen in period $t$, where $\mathcal{F}_{i, t+1} \subseteq \mathcal{X}^{n}$. The friend set $\mathcal{F}_{i, t+1}$ determines the next period's peer quality $\bar{\theta}_{i, t+1}$. The friendship decisions, in turn, hinge on both the child's and the parent's decisions in a way that will be made precise below. ${ }^{15}$ The (conditional) expectation in the value function reflects the presence of taste shocks affecting the process of friendship formation. Current peer quality $\bar{\theta}_{i, t}$ enters the value function because it affects the evolution of the child's skills and the decisions of parents.

The representation of preferences in Equation (1) implies that children only care about the flow utility accruing from spending time with their friends with no regard for the effects of peers on their skill formation. A more general representation could include the discounted continuation utility from the next period

\footnotetext{
${ }^{14}$ In principle, because there is a finite number of families in each neighborhood, peer interactions imply there is a feedback from a family's decisions to the aggregate state, i.e., each family affects skill accumulation in other families. In practice, given the size of neighborhoods in the estimated model, this feedback effect is very small, so we assume that parents take the skill distribution in the neighborhood as given.

${ }^{15}$ Note that given that utility is summarized after friendship formation at time $t$ has already been completed, the utility derived from forming friendships with time- $t$ friends $u\left(\mathcal{F}_{i, t}\right)$ does not appear in the time- $t$ value function (instead, it appears at time $t-1$ ).
} 
onward. ${ }^{16}$ In other words, we ignore the possibility that children strategically prefer peers with high grades because of the help these peers may offer them in improving their school proficiency. This assumption simplifies our empirical analysis by allowing us to obtain analytical expressions that can be estimated directly. The loss of generality relative to the formulation in Footnote 16 is very limited. In our estimation, children take into account the value of other children's skills because these affect (as we will see) the value of being friends with them. Therefore, the ultimate determinants of their choice would be the same as in our formulation, although the functional forms would be different.

The parent's total utility in period $t$ is given by the value function:

$$
\begin{aligned}
V_{t}^{n}\left(\theta_{i, t}, \bar{\theta}_{i, t}\right) & =\max \left\{\mathrm { E } \left[U\left(I_{i, t}, P_{i, t}, \epsilon_{i, t}\right)+\right.\right. \\
Z & {\left.\left.\left[\lambda \tilde{u}\left(\theta_{i, t}, P_{i, t}\right)+(1-\lambda) u\left(\mathcal{F}_{i, t+1}\right)\right]+B V_{t+1}^{n}\left(\theta_{i, t+1}, \bar{\theta}_{i, t+1}\right) \mid \theta_{i, t}, \bar{\theta}_{i, t}\right]\right\} . }
\end{aligned}
$$

Here $U\left(I_{i, t}, P_{i, t}, \epsilon_{i, t}\right)$ is the parent's period utility, which depends on parenting style $\left(P_{i, t}\right.$ and $\left.I_{i, t}\right)$, chosen optimally by the parent. Utility also depends on taste shocks $\epsilon_{i, t}$, which ensure a smooth mapping from state variables into decisions. The parent also cares about the child, where $Z$ is the overall weight attached to the child's welfare.

Parental concern about children has an altruistic and a paternalistic component. The altruistic component with weight $1-\lambda$ consists of the child's actual period utility $u\left(\mathcal{F}_{i, t+1}\right)$. The paternalistic component with weight $\lambda$ is the parent's own evaluation of the current actions and outcomes of the child. The paternalistic concern is focused on the child's accumulation of skills $\theta_{i, t}$, where we allow for the possibility that the parent's evaluation of the child's skill interacts with parenting style $P_{i, t}$. Hence, paternalistic utility enters as $\tilde{u}\left(\theta_{i, t}, P_{i, t}\right)$. Note that, at time $t$, the parent takes the quality of the child's current peers $\bar{\theta}_{i, t}$ as given, but the parent can influence future peer formation (and hence future peer quality $\bar{\theta}_{i, t+1}$ ) through

\footnotetext{
${ }^{16}$ Formally, the more general representation would be

$$
v_{t}^{n}\left(\theta_{i, t}, \bar{\theta}_{i, t}\right)=\max \left\{\mathrm{E}\left[u\left(\mathcal{F}_{i, t+1}\right)+b v_{t+1}^{n}\left(\theta_{i, t+1}, \bar{\theta}_{i, t+1}\right) \mid \theta_{i, t}, \bar{\theta}_{i, t}\right]\right\} .
$$
}

Our myopic formulation corresponds to setting $b=0$. 
the choice of parenting style $P_{i, t} \cdot{ }^{17}$

The continuation utility at the end of high school is identical to the child's continuation utility, and thus depends on $\theta_{T+1}$ :

$$
V_{T+1}^{n}=v_{T+1}^{n}\left(\theta_{i, T+1}\right),
$$

where the function $v_{T+1}^{n}\left(\theta_{T+1}\right)$ (corresponding to the child's utility as an adult) is taken as given and assumed to be identical across neighborhoods.

Taking stock, the focal point of the theory is a disagreement between the parent and the child about the tradeoff between the enjoyment of the present (i.e., interactions with friends) and investment in future skills. For instance, a child may want to hang out with "cool" kids who do not necessarily do well in school, whereas associating with "nerdy" high-GPA peers may be good for school performance but also more boring for the child.

\subsection{The Technology of Skill Formation}

Having described preferences, we now turn to the technology of skill formation for adolescent children. The initial distribution of children's skills is drawn from the distribution $F^{n}\left(\theta_{i, 1}\right)$. In reality, this initial distribution depends on families' socio-economic conditions, neighborhood effects, and earlier actions by parents and children. Since we do not have information on those variables before children enter high school, we treat initial conditions as exogenous. ${ }^{18}$

Subsequently, skills evolve as a function of family inputs and peer influences. For each child $i$, next period's skill $\theta_{i, t+1}$ depends on the current stock of skills $\theta_{i, t}$, a summary statistic of the quality of peers $\bar{\theta}_{i, t}$ (e.g., the average level of skills), parental investments $I_{i, t}$, and the parent's choice of whether to interfere in the

\footnotetext{
${ }^{17}$ The disagreement between parents and children does not hinge on the simplifying assumption that children are myopic. We could obtain the same results if we replaced Equation (1) with the more general formulation given in Footnote 16. Disagreement could arise both through the parametrization of the functions $u$ and $\tilde{u}$ in Equation (2), which reflect the within-period disagreement between parent and child, and through allowing for the possibility that the parent's discount factor $B$ is larger than the child's discount factor $b$.

${ }^{18}$ As we discuss below, we estimate the model using only within-school-grade variation in the data.
} 
child's choice of peers $P_{i, t} \in\{0,1\}$. We formalize the technology of skill formation as follows:

$$
\theta_{i, t+1}=s\left(\theta_{i, t}, \bar{\theta}_{i, t}, I_{i, t}, P_{i, t}\right) .
$$

The direct effect of parenting style $P_{i, t}$ in Equation (3) captures the impact of the quality of the parent-child relationship on skill accumulation. While we do not impose any a priori restriction in the estimation, we expect an authoritarian parenting style to have a negative effect on skill accumulation. This could arise either from discord between parent and child or from time use: time that the parent spends trying to talk kids out of meeting certain people is not available for more productive investments. The total effect of an authoritarian parenting style can still be positive because $P_{t}$ affects the composition of the peer group and hence peer quality $\bar{\theta}_{i, t}$.

\subsection{Endogenous Peer Selection}

We model the formation of friendships as a random utility model. Every period, each child meets all potential peers $\mathcal{X}^{n}$ in the neighborhood and can try to be friends with some of them. There is no capacity constraint in the number of friends nor any decreasing marginal utility to the number friendships. The potential utility $f_{i, j, t+1}$ that child $i$ would derive from forming a new friendship with $j \in \mathcal{X}^{n}$ is given by:

$$
f_{i, j, t+1}=g\left(\theta_{i, t+1}, \theta_{j, t+1}, P_{i, t}, \eta_{i, j, t+1}\right) .
$$

Here $\eta_{i, j, t+1}$ is an independent and identically distributed (i.i.d.) taste shock that guarantees that the probability that a friendship is established is a smooth function of fundamentals. Note that, in general, $\eta_{i, j, t+1} \neq \eta_{j, i, t+1}$, which captures the common situation where, say, child $i$ wants to be friends with $j$ but not vice versa. The utility from forming a friendship depends on both the own skill of child $i$ and the skill of the potential friend $j$. This specification allows for homophily bias in terms of skills. ${ }^{19}$

\footnotetext{
${ }^{19}$ The homophily bias is a common tendency of people in social networks to be drawn toward others who are similar to them in some significant dimension (see e.g., McPherson, Smith-Lovin, and Cook 2001; Currarini, Jackson, and Pin 2009; Jackson 2010, and, in a context similar to ours, Agostinelli 2018).
} 
The parenting style $P_{i, t}$ affects how much utility accrues to the child when it forms friendships with children of different skill levels. Since parents want to encourage skill formation, we assume that an authoritarian parenting style $\left(P_{i, t}=\right.$ 1) lowers the utility of befriending a low-skill peer relative to a high-skill one. This could be done by rewarding the child in some way for making "desirable" friends or by meting out punishments for befriending less desirable ones.

Friendships are subject to mutual agreement: a friendship between child $i$ and child $j$ is formed if and only if

$$
f_{i, j, t+1}>0 \& f_{j, i, t+1}>0
$$

where we normalize the value of not forming a friendship to zero. As already mentioned, $\mathcal{F}_{i, t+1} \subseteq \mathcal{X}^{n}$ denotes the set of friendships involving child $i$ in period $t+1$, i.e., the set of $j \in \mathcal{X}^{n}$ for which Equation (5) is satisfied. The friendship utility $u\left(\mathcal{F}_{i, t+1}\right)$ that determines the child's utility (1) is then:

$$
u\left(\mathcal{F}_{i, t+1}\right)=\sum_{j \in \mathcal{F}_{i, t+1}} f_{i, j, t+1} .
$$

The process of friendship formation entails externalities across families. Friendships are formed by mutual consent. When a parent meddles in the process of friendship formation, her intervention affects not only her child, but also other children. Given that parents do not care about other children, their decisions generally fail to be socially optimal.

\subsection{Friendship Formation in the First and Last Periods}

The value functions (1) and (2) in the first period (corresponding to ninth grade) depend on the initial quality of peers $\bar{\theta}_{i, 1}$. Rather than taking this state variable as parametric, we assume that only the initial distribution of skills is given and that friendships are formed through the endogenous process discussed above. This approach allows us to run policy analyses where we counterfactually vary the initial skill distribution and adjust the network of friends accordingly. A limitation is that we do not observe parenting style in the preceding period. For this 
reason, we assume that parents cannot affect the initial choice of friends. ${ }^{20}$ Since this happens in the period when children enter high school and are exposed to new peers, this entails only a limited loss of generality.

In the last period $T=4$ (corresponding to 12th grade), the parental decision problem is different because the continuation utility $V_{T+1}^{n}$ does not depend on the quality of peers. This reflects that the children have to form new peer groups after leaving high school, and at any rate these future peers are not observed in the Add Health data. Setting $P_{i, T}=1$ does not affect future peers' skills, and parenting style will be optimally chosen solely based only on the parents' taste shocks.

\subsection{Functional Forms for Estimation}

To estimate the model, we impose functional forms and restrictions that allow us to summarize the model by a list of parameters.

Initial Conditions. The initial distribution of children skills within each neighborhood $n$ is drawn from a log-normal distribution. This specification captures the initial (and to us unobserved) sorting of families into different neighborhoods characterized by different initial distributions of children's skills. We define the initial conditions for each neighborhood $n$ as follows:

$$
\ln \theta_{i, 1} \sim N\left(\mu^{n},\left(\sigma^{n}\right)^{2}\right),
$$

where $\mu^{n}$ and $\sigma^{n}$ represent the neighborhood-specific mean and the standard deviation of the log-skills.

Once the initial heterogeneity of children's skills within the neighborhood is realized, children select their initial peer group according to their preferences for friends (Equation (4)). ${ }^{21}$ At this stage, the initial vector of state variables $\left\{\theta_{i, 1}, \bar{\theta}_{i, 1}\right\}$

\footnotetext{
${ }^{20}$ Formally, we set $P_{i, t-1}=0$ when evaluating Equation (4) and Equation (5) at time $t=1$.

${ }^{21}$ As noted, we do not have information about parenting style at time $t=0$. Note that in our sample, children start high school at time $t=1$, where they meet many new potential friends. For this reason, we find it plausible to assume that parents have a limited effect on the process of selection in the first period.
} 
is determined, and the dynamic parent-child interaction starts according to the model described above. ${ }^{22}$

Technology of Skill Formation. We parameterize the technology of skill formation with the following nested CES production function:

$$
s\left(\theta_{i, t}, \bar{\theta}_{i, t}, I_{i, t}, P_{i, t}=p\right)=A_{p}(t) \times H_{p}\left(\theta_{i, t}, \bar{\theta}_{i, t}, I_{i, t}\right),
$$

where $p \in\{0,1\}, A_{p}(t)=\exp \left(\psi_{0}+\psi_{1} \cdot t+\psi_{2} \cdot p\right)$, and

$$
H_{p}\left(\theta_{i, t}, \bar{\theta}_{i, t}, I_{i, t}\right)=\left[\alpha_{1, p} \theta_{i, t}^{\alpha_{4, p}}+\left(1-\alpha_{1, p}\right)\left[\alpha_{2, p} \bar{\theta}_{i, t}^{\alpha_{3, p}}+\left(1-\alpha_{2, p}\right) I_{i, t}^{\alpha_{3, p}}\right]^{\frac{\alpha_{4, p}}{\alpha_{3, p}}}\right]^{\frac{\alpha_{5, p}}{\alpha_{4, p}}} .
$$

Note that all parameters of the skill formation technology depend on $P$, namely, whether the parent chooses an authoritarian parenting style. First, this affects the total factor productivity $A_{p}(t)$, capturing the potential disruptive effect of authoritarian parenting on the parent-child relationship documented by the developmental psychology literature. Our estimation below indeed finds that $\psi_{2}<0$, i.e., an authoritarian parenting style depresses skill accumulation. Second, parenting style affects the parameters $\alpha_{1, p}$ and $\alpha_{2, p}$, capturing the weights of the different inputs. Our estimation finds that the authoritarian style attenuates the influence of peers. Third, an authoritarian parenting style also affects the elasticityof-substitution parameters $\alpha_{3, p}$ and $\alpha_{4, p}$ and the returns-to-scale parameter $\left(\alpha_{5, p}\right)$. Here the data suggest the parenting style determines whether peer effects are a substitute or a complement to other inputs in the production of skills.

Parent's Preferences. We specify the parent's period utility in (2) as follows:

$$
U\left(I_{i, t}, P_{i, t}, \epsilon_{i, t}\right)=\delta_{1} \ln \left(1-I_{i, t}\right)+\delta_{2} P_{i, t}+\epsilon_{i, t}\left(P_{i, t}\right),
$$

where $\delta_{1}$ and $\delta_{2}$ define the disutility of authoritative investment and of engaging in an authoritarian parenting style, respectively, and $\epsilon_{i, t}\left(P_{i, t}\right)$ is a taste shock

\footnotetext{
${ }^{22}$ An alternative specification for the initial conditions would be to specify an exogenous bivariate joint distribution of children's skills and peer quality. However, in this case the initial peer quality would be exogenously determined and hence policy-invariant. Our model specification allows for immediate endogenous peer selection, which is important when evaluating policies that change the initial neighborhood composition, as we do below.
} 
that is conditional on the parenting style. We assume that this shock follows a type-I extreme value distribution. The paternalistic utility of the parent takes the following form:

$$
\tilde{u}\left(\theta_{i, t}, I_{i, t}, P_{i, t}\right)=\delta_{3} \ln \left(\theta_{i, t}\right) \cdot\left(1+\delta_{4} P_{i, t}\right),
$$

where $\delta_{3}$ captures the level of the parent's paternalistic enjoyment of the child's skills, which may depend on the parenting style through parameter $\delta_{4}$. The utility derived from the child's adult skills $\theta_{i, T+1}$ takes the same form as the period-byperiod paternalistic utility from skills:

$$
V_{T+1}^{n}=\delta_{3} \ln \left(\theta_{i, T+1}\right) .
$$

In the empirical model, we set $Z=B=1$. This is without loss of generality. An increase in either $B$ or $Z$ is equivalent to a proportional decrease in cost parameters $\delta_{1}$ and $\delta_{2}$. Changing $B$ and/or $Z$ would affect the numerical estimates of those parameters without altering the model fit or the counterfactual experiments.

Child's Preferences. The (marginal) utility child $i$ earns from being friends with child $j$ relative to not being friends with $j$ is:

$$
\begin{aligned}
f_{i, j, t+1}=\gamma_{0}+\gamma_{1} \ln \theta_{i, t+1}+\gamma_{2} \ln \theta_{j, t+1}+\gamma_{3}\left(\ln \theta_{i, t+1}-\ln \theta_{j, t+1}\right)^{2} \\
+\gamma_{4} \mathbb{\mathbb { 1 }}\left(\theta_{j, t+1}<\theta_{i, t+1}\right)\left(\ln \theta_{i, t+1}-\ln \theta_{j, t+1}\right)^{2} P_{i, t}+\eta_{i, j, t+1} .
\end{aligned}
$$

Here, $\eta_{i, j, t+1}$ is a random taste shock for being friends with child $j$, which we assume to be i.i.d. standard logistic distributed. The terms $\gamma_{1} \ln \theta_{i, t+1}$ and $\gamma_{2} \ln \theta_{j, t+1}$ capture, respectively, the effect of child $i$ 's and child $j$ 's skills on the utility child $i$ earns from being friends with child $j$, where $\gamma_{1}$ and $\gamma_{2}$ are parameters that will be estimated. The quadratic term $\left(\ln \theta_{i, t+1}-\ln \theta_{j, t+1}\right)^{2}$ captures potential homophily bias in the formation of friends. A negative coefficient $\gamma_{3}<0$ would imply that the higher the difference in skills between the two children, the lower the utility for child $i$ to be friends with child $j$.

The coefficient $\gamma_{4}$ captures the effect of an authoritarian parenting style on the preferences for child $j^{\prime}$ s skills. In particular, if $\gamma_{4}<0$, authoritarian parenting 
imposes a penalty whenever the child is friends with a lower-skill peer, where the penalty increases with the GPA gap between the two children. This formulation captures the idea that parental intervention (through, e.g., moral suasion, threat of punishment, or incentives) is designed to improve the quality of the child's peer selection.

We can now characterize the conditional probability that a friendship link between child $i$ and child $j$ is formed as: $:^{23}$

$$
\operatorname{Pr}\left(j \in \mathcal{X}_{i, t+1} \mid \theta_{i, t+1}, P_{i, t}, \theta_{j, t+1}, P_{j, t}\right)=\frac{\exp \left(\Gamma_{i, j}\right)}{1+\exp \left(\Gamma_{i, j}\right)} \frac{\exp \left(\Gamma_{j, i}\right)}{1+\exp \left(\Gamma_{j, i}\right)},
$$

where:

$$
\begin{aligned}
\Gamma_{i, j}=\gamma_{0}+\gamma_{1} \ln \theta_{i, t+1}+\gamma_{2} \ln \theta_{j, t+1} & +\gamma_{3}\left(\ln \theta_{i, t+1}-\ln \theta_{j, t+1}\right)^{2} \\
& +\gamma_{4} \mathbb{1}\left(\theta_{j, t+1}<\theta_{i, t+1}\right)\left(\ln \theta_{i, t+1}-\ln \theta_{j, t+1}\right)^{2} P_{i, t}, \\
\Gamma_{j, i}=\gamma_{0}+\gamma_{1} \ln \theta_{j, t+1}+\gamma_{2} \ln \theta_{i, t+1} & +\gamma_{3}\left(\ln \theta_{j, t+1}-\ln \theta_{i, t+1}\right)^{2} \\
& +\gamma_{4} \mathbb{1}\left(\theta_{i, t+1}<\theta_{j, t+1}\right)\left(\ln \theta_{i, t+1}-\ln \theta_{j, t+1}\right)^{2} P_{j, t} .
\end{aligned}
$$

The presentation of the parent's and child's preferences completes the description of the effects of parenting style in our model. To summarize, authoritarian parenting has a direct effect on the technology of skill formation given the current child's skill and peers. In addition, authoritarian parenting affects the process of peer formation by discouraging the child from choosing low-skill friends. Our estimates below imply that, conditional on an existing set of friends, an authoritarian parenting style entails productivity losses in the skill formation technology. The reason some parents still choose to be authoritarian must then lie in the benefits of an improved quality of future peers. It follows from this argument

\footnotetext{
${ }^{23}$ The conditional probability in Equation (11) might suggest a potential strategic interaction between parents when deciding about their own parenting style. However, under our assumptions, only the parent of the higher-skill child can actively affect the probability in Equation (11), so there is in fact no strategic interaction among parents. Note that in our model parents have an additional motive to invest in their children's skills, namely, to give them more opportunities to condition their children's choice of peers in the future.
} 
that in wealthy and homogeneous neighborhoods, where most potential friends are highly skilled and there is little risk that one's child might associate with lowskill peers, the cost of an authoritarian parenting style is high while the benefit is small. Conversely, parents will tend to be authoritarian in neighborhoods where children face a high risk of exposure to low-skill peers.

\section{Model Estimation}

We estimate the model using the Simulated Method of Moments (SMM) by matching a set of moments generated from the Add Health data. More specifically, we follow an indirect inference approach where some of the target moments are estimated coefficients of reduced-form regressions including school-grade fixed effects.

We take the initial distribution of skills as exogenous, assuming that these are a sufficient statistic for fixed characteristics and past history, including innate ability, socio-economic status, parental behavior before adolescence, and random shocks, which we do not observe in our data. ${ }^{24}$ Since residential choice can lead to ex ante sorting of families with different characteristics, we do not use the variation across schools in the estimation. ${ }^{25}$ Instead, we identify the parameters using within-school-grade variation in the data. After the first period, heterogeneity in skills and exposure to peers is partly endogenous (as determined by the laws of motion of the model) and partly determined by preference shocks.

We target the following 28 moments:

1. Probability of parents being authoritarian: Aggregate fraction and regression of parenting style on current period own child's and peers' skills (three moments, see Table A-3).

\footnotetext{
${ }^{24}$ Appendix B provides details on the way we measure children's skills.

${ }^{25}$ The results are robust to controlling for parental education as discussed below (see Appendix C.2 and Table C2-1). One might still be concerned about selection by unobserved heterogeneity before high school starts. The mobility of the families with teenagers that enter our sample is, in contrast, rather low. Therefore, selection is a less severe concern when we compare pupils within school and grade.
} 
2. Dynamics of a child's skills: Mean by school grades and regressions of a child's next-period skills on previous period own skills, peers' skills, and authoritarian parenting style (eleven moments, see Table A-4).

3. Dynamics of peers' skills: Number of friends and regressions of next-period peers' skills on previous period own skills, peers' skills, and authoritarian parenting style (eight moments, see Table A-5).

4. Parental investment: Mean and regressions of parental investments on current period own skills, peers' skills, and authoritarian parenting style (six moments, see Table A-6).

To estimate the model, we must define the neighborhoods in which children form friendships and solve for a local equilibrium in each neighborhood. A natural choice would be to have as many environments as there are schools in our sample. However, when implementing a simulation-based estimator, this approach becomes computationally infeasible. To overcome this issue, we pursue a parsimonious approach where a neighborhood is characterized by the mean and standard deviation of a log-normal distribution of initial skills. We carry out the estimation using synthetic neighborhoods based on the variation across schools observed in the Add Health sample. Specifically, we sort schools by average child skills and then form four synthetic neighborhoods from the quartiles of this distribution.

Table 4 summarizes the characteristics of these neighborhoods (from the lowest to the highest quartile). Using the data, we can map the quartiles of the skill distribution to quartiles of the income distribution. As expected, average grades are higher in high-income neighborhoods. The median real family incomes in 2016 US dollars for the four synthetic neighborhood are $\$ 5,000$ (Neighborhood 1), $\$ 48,000$ (Neighborhood 2), $\$ 81,000$ (Neighborhood 3), and $\$ 102,000$ (Neighborhood 4).

We first report the parameter estimates, then turn to the fit of the model to the target moments, and finally discuss the fit to untargeted moments. 
Table 4: Characteristics of Synthetic Neighborhoods

\begin{tabular}{lccc}
\hline \hline & Mean $\left(\mu_{e}\right)$ & Standard Deviation $\left(\sigma_{e}\right)$ & Population \\
\cline { 2 - 4 } Neighborhood 1 & -0.55 & 0.87 & 269 \\
Neighborhood 2 & -0.28 & 0.98 & 307 \\
Neighborhood 3 & 0.23 & 0.96 & 300 \\
Neighborhood 4 & 0.59 & 0.84 & 210 \\
\hline \hline
\end{tabular}

The table shows the mean and standard deviation of grades (from log-normal distributions) in four synthetic neighborhoods. The associated distributions are the initial conditions in the structural estimation of the dynamic model of skill formation.

\subsection{Parameter Estimates}

Skill Formation Technology. Table 5 displays the estimates of the parameters of the skill formation technology in Equation (7). Recall that the parameters are different for parents adopting an authoritarian $(P=1)$ and a nonauthoritarian $(P=0)$ parenting style. For $P=1$, we obtain estimates of the two elasticities of substitution close to unity. ${ }^{26}$ Therefore, we report estimates of a parsimonious model in which we impose a Cobb-Douglas production such as:

$$
H\left(\theta_{i, t}, \bar{\theta}_{i, t}, I_{i, t}, 1\right)=\theta_{i, t}^{\bar{\alpha}_{1,1}} \bar{\theta}_{i, t}^{\bar{\alpha}_{2,1}} I_{i, t}^{\bar{\alpha}_{3,1}}
$$

where $\bar{\alpha}_{1,1}=\alpha_{1,1} \alpha_{5,1}, \bar{\alpha}_{2,1}=\left(1-\alpha_{1,1}\right) \alpha_{2,1} \alpha_{5,1}$, and $\bar{\alpha}_{3,1}=\left(1-\alpha_{1,1}\right)\left(1-\alpha_{2,1}\right) \alpha_{5,1}$.

In contrast, the estimated elasticities are significantly different from unity for nonauthoritarian parents. Consider, first, $\alpha_{4,0}$. When $P=0$, we estimate $\alpha_{4,0}>0$, which implies that parental investment and peer quality are substitutes, as in Agostinelli (2018). This elasticity is primarily identified by the covariation between inputs in the technology of skill formation. For authoritarian parents, parental investment barely responds to the skills of the child and the peers, consistent with a unit elasticity. In contrast, nonauthoritarian parents spend more time with their children when the peer group is weak, consistent with an elasticity of substitution larger than unity.

The estimates of the other parameters also reveal interesting patterns. An author-

\footnotetext{
${ }^{26}$ The point estimates for the unconstrained CES specification are $\alpha_{1, p}=0.772, \alpha_{2, p}=0.382$, $\alpha_{3, p}=0.009, \alpha_{4, p}=0.009$, and $\alpha_{5, p}=0.502$. See Appendix Table C1-1.
} 
Table 5: Estimated Parameters of the Skill Formation Technology

\begin{tabular}{lc}
\hline \hline & Cobb-Douglas $($ Authoritarian $=1)$ \\
\cline { 2 - 2 } Child's Skills $\left(\alpha_{1,1}\right)$ & 0.412 \\
Peer Skills $\left(\alpha_{2,1}\right)$ & {$[0.321,0.460]$} \\
Investments $\left(\alpha_{3,1}\right)$ & 0.214 \\
& {$[0.168,0.370]$} \\
& 0.073 \\
Complementarity Parents vs. Peers $\left(\alpha_{4,0}\right)$ & {$[0.045,0.095]$} \\
Share Self-Production $\left(\alpha_{1,0}\right)$ & CES (Authoritarian $=0)$ \\
Share Peer Skills $\left(\alpha_{2,0}\right)$ & {$[0.755,0.801]$} \\
Complementarity Self-Production vs. Parents-Peers $\left(\alpha_{3,0}\right)$ & 0.564 \\
CES Returns to Scale $\left(\alpha_{5,0}\right)$ & {$[0.558,0.569]$} \\
TFP Parenting Style $\left(\psi_{2}\right)$ & 0.395 \\
TFP Constant $\left(\psi_{0}\right)$ & {$[0.385,0.404]$} \\
& -1.680 \\
\hline \hline & {$[-1.767,-1.587]$} \\
& {$[1.046,1.175]$} \\
& {$[0.326,-0.280]$} \\
\hline
\end{tabular}

The table shows the estimated parameters of the skill formation technology. See Equation (7) for $P=0$ and Equation (12) for $P=1$. The 95 percent confidence intervals in brackets are calculated via 100 school-clustered bootstrap repetitions. The point estimates are the averages among the bootstrap repetitions.

itarian parenting style reduces both the total factor productivity and the relative importance of peer effects. ${ }^{27}$ Both results are intuitive and in line with the findings of the child development literature. For nonauthoritarian parents, we find a strong complementarity between the child's skills and the composite input of peer effects and parental investments $\left(\alpha_{3,0}<0\right)$. In plain words, nonauthoritarian parents invest more time when the child has high skill. This complementarity has an important implication: a combination of nonauthoritarian parenting

\footnotetext{
${ }^{27}$ In Appendix C.1, Tables C1-2 and C1-3, we estimate two specifications imposing that authoritarian and nonauthoritarian parents operate the same technology of skill formation. The fit of the model deteriorates significantly suggesting that a tradeoff between the influence on peer selection and the direct effect on human capital accumulation is an essential feature of the choice of parenting style in our theory.
} 
and authoritative investments is highly productive for gifted children. Therefore, high-skill children are less likely to be subject to an authoritarian parenting style and more likely to attract other types of time-intensive (authoritative) parental investments. This insight casts a new light on the conventional wisdom in the child development literature that an authoritarian parenting style leads to poor child outcomes. This wisdom is rooted in the positive correlation found in observational data. Our structural theory implies that children with low cognitive or noncognitive abilities are more likely to attract an authoritarian parenting style. Thus, part of the correlation observed in the data might reflect (and according to our estimates, indeed does reflect) a reverse causation.

Table 6: Estimated Parent's Preference Parameters

\begin{tabular}{lc}
\hline \hline & 1 \\
Disutility of Investment $\left(\delta_{1}\right)$ & $($ Normalized) \\
& {$[-,-]$} \\
Disutility of Authoritarian $\left(\delta_{2}\right)$ & -2.208 \\
& {$[-2.516,-2.084]$} \\
Child's Skills $\left(\delta_{3}\right)$ & 2.184 \\
& {$[2.049,2.336]$} \\
Authoritarian $\times$ Child's Skills $\left(\delta_{4}\right)$ & -0.208 \\
& {$[-0.225,-0.173]$} \\
\hline
\end{tabular}

The table shows the estimated parents' preference parameters;
see Equations (8) and (9). The 95 percent confidence intervals in
brackets are calculated via 100 school-clustered bootstrap rep-
etitions. The point estimates are the averages among the boot-
strap repetitions.

Preferences. Table 6 displays the estimates of parents' preferences. In the estimation, we exogenously set $\lambda=0.95$, i.e., parents are highly paternalistic. It is difficult to find sources of variation in the data to credibly identify this parameter. The results are rather insensitive to changes in $\lambda$, as long as we stay in a high range. For lower values of $\lambda$, we cannot match the observed share of authoritarian parents. ${ }^{28}$ According to our estimates, parents dislike being authoritarian $\left(\delta_{2}<0\right)$, and more so when children have high skills $\left(\delta_{4}<0\right)$.

\footnotetext{
${ }^{28}$ The results are very similar for any $\lambda \geq 0.9$. One could construct an alternative model where $\lambda$ varies across parents and only some of them choose an authoritarian parenting style. This model would yield similar results.
} 
Table 7: Estimated Child's Preference Parameters

\begin{tabular}{lc}
\hline \hline & \\
Child $i$ 's Skills $\left(\gamma_{1}\right)$ & -0.184 \\
& {$[-0.199,-0.173]$} \\
Child $j$ 's Skills $\left(\gamma_{2}\right)$ & -0.191 \\
& {$[-0.201,-0.177]$} \\
Homophily $\left(\gamma_{3}\right)$ & -0.286 \\
& {$[-0.320,-0.266]$} \\
Authoritarian $\left(\gamma_{4}\right)$ & -0.468 \\
& {$[-0.502,-0.384]$} \\
Constant $\left(\gamma_{0}\right)$ & -1.484 \\
& {$[-1.517,-1.438]$} \\
\hline \hline
\end{tabular}

The table shows the estimated child's preference arameters, see Equation (10). The 95 percent confidence intervals in brackets are calculated via 100 school-clustered bootstrap repetitions. The point estimates are the averages among the bootstrap repetitions.

Table 7 shows the estimates for the child's preferences in the random utility model. The coefficients of own and peer skills are both negative, indicating that high-skill children are both less keen on forming friendship ties and less popular with other children. Intuitively, from a child's perspective, low-skill peers are more attractive friends than "nerdy" high achievers. The estimate of the homophily parameter has a negative sign. As this parameter multiplies the squared difference between own and peer skills, the negative point estimate implies a positive homophily bias, i.e., the larger the difference in skills between the two children, the less valuable the friendship. The parameter $\gamma_{4}$ captures the penalty from socializing with low-skill peers when parents are authoritarian. This penalty is quantitatively large: the estimate is almost twice the size of the homophily coefficient $\gamma_{3}$. Thus, an authoritarian parenting style has a strong causal effect on the child's future peer selection.

These estimation results paint a clear picture of the tradeoff involved in the choice of parenting style. An authoritarian parenting style entails a productivity loss in the skill formation technology but improves peer selection over time. Being authoritarian is therefore more attractive in poor neighborhoods, where the benefit 
of improving the selection of friends is large. Also, all else being equal, it is the parents of children with many low-skill friends who have the strongest incentive to behave in an authoritarian fashion because their children's skill formation benefits little from their current peers. Finally, the (authoritative) time investment responds more to the quality of peers if the parent is nonauthoritarian. Specifically, parents who give children leeway spend more time with them when the quality of the peer environment is low. For all these reasons, parents are less prone to be authoritarian in wealthier neighborhoods.

\subsection{Robustness: Heterogenous Effects by Education}

In our main estimation, we kept the structural model parsimonious by limiting initial heterogeneity (before the first friendships are formed) to the single dimension of skill. A potential concern is that parenting style may correlate with and be partly determined by other characteristics that the model abstracts from. If so, the effect of parenting style could spuriously proxy for the effect of another variable.

A characteristic that is especially likely to be relevant is parental education, which is correlated with parenting style and could have independent effects on child development. To address this concern, we re-estimate the model while allowing for some of the key parameters to vary with parental education. We focus on mother's education to avoid selection problems related to the fact that in many families, fathers are not present. We distinguish between mothers with high education (some college or more) and with low education (high school or less). We allow this binary measure of mother's education to affect the preferences for parenting style and the total factor productivity in the skill formation technology. Arguably, these are the two most natural differences related to education. More educated mothers may dislike being authoritarian, and they may enhance the productivity of the technology of skill formation irrespective of the parenting style.

We find that parameters we assume to be independent of mother's education are estimated to be very similar to those estimated in the benchmark model. In the more flexible model, highly educated mothers have a higher cost of being au- 
thoritarian and induce higher total factor productivity in the technology of skill formation. However, in neither case is the difference quantitatively large. ${ }^{29}$ The estimation results suggest that allowing for heterogeneity in parents' education is not essential, at least during the high school years that we focus on. We therefore use the more parsimonious model without a direct role for parental education.

\subsection{Sample Fit}

Tables A-3 through A-6 report information about the sample fit of the model. Recall that the model is estimated by indirect inference, i.e., the SMM estimation targets the regression coefficients from the data. All regressions, both in the data and in the model, include school-grade fixed effects. The tables show how successful the simulated model is in matching the targeted moments.

Table A-3 focuses on the results of linear probability models where $P=1$ (i.e., being authoritarian) is regressed on the child's and the peers' skills. For the reasons discussed above, parents are less likely to interfere with peer formation when their own children are proficient and when the peer group is of high quality. The model closely matches the sign and magnitude of the coefficients and also accurately predicts the total fraction of authoritarian parents.

Table A-4 displays results for the dynamics of skills. In the upper panel, the child's next-period skills are regressed on her own current skills, the average skills in her peer group, and the parenting style to which she is subjected. Both in the model and in the data, the coefficient of the child's skills is the largest; the coefficient of the peers' skills is smaller and yet sizeable. Both in the model and in the data, the reduced-form effect of parenting style on the next period's skills is small..$^{30}$ In particular, the point estimate is negative in the model and positive

\footnotetext{
${ }^{29}$ The results can be found in Appendix C.2.

${ }^{30}$ In the data, the effect is positive but statistically insignificant. Interestingly, the regression coefficient turns positive and highly significant if we restrict the sample to intact (i.e., two-parent) families. In the data the small size of the effect is largely explained by families with single mothers-a similar argument applies to Table A-5 below. Since our model abstracts from this dimension, we conservatively target the small positive coefficient that we find for all families. Our structural estimate implies a large causal effect of an authoritarian parenting style even though the targeted reduced-form effect (that is confounded by selection issues) is small. The causal effect would be even larger if we targeted the regression coefficient for intact families.
} 
but statistically insignificant in the data. The lower panel shows the evolution of mean skills throughout the high school years in the model and in the data. Again, the fit is very good.

Table A-5 compares the regression coefficients for the evolution of peer skills in the model and in the data. In the data, the correlation of authoritarian parenting with the quality of peers in the next period is insignificant. Interestingly, the correlation is also low in the linear regression generated by the model, in spite of the large positive causal effect of authoritarian parenting on the selection of peers discussed above.

Table A- 6 displays results for authoritative parental investments broken down by (authoritarian versus nonauthoritarian) parenting style. For authoritarian parents, time investments are unresponsive to both the child's and the peers' skills. The model accounts for this finding by estimating a unit elasticity (Cobb Douglas) in the skill formation technology. In contrast, when $P=0$ parental investments are positively associated with the child's skills and negatively associated with the peers' skills. The model accounts for this pattern by estimating a higher elasticity of substitution in the CES technology, as discussed above. Note that the average level of investment also strongly depends on the parenting style, with a good fit between the model and data.

\subsection{Fit for Non-Targeted Moments: Parenting Across Neighborhoods}

In this section, we assess the accuracy of the estimated model in matching nontargeted moments. We compare the model predictions with data moments across the four synthetic neighborhoods that determine the peer environment. Recall that our estimation targets the coefficients of linear regressions exploiting withinschool-grade variation. Since we did not target any variation across neighborhoods, this variation is an ideal testing ground to evaluate the success of the model in fitting non-targeted moments.

Figure 3 shows the fraction of authoritarian parents in each neighborhood predicted by the model and its empirical counterpart, namely, the average across all the schools that make up a synthetic neighborhood. In the data, the fraction of authoritarian parents is strongly decreasing as one moves from the less to the 
Figure 3: Out-of-Sample Fit: Parenting Style and Neighborhood

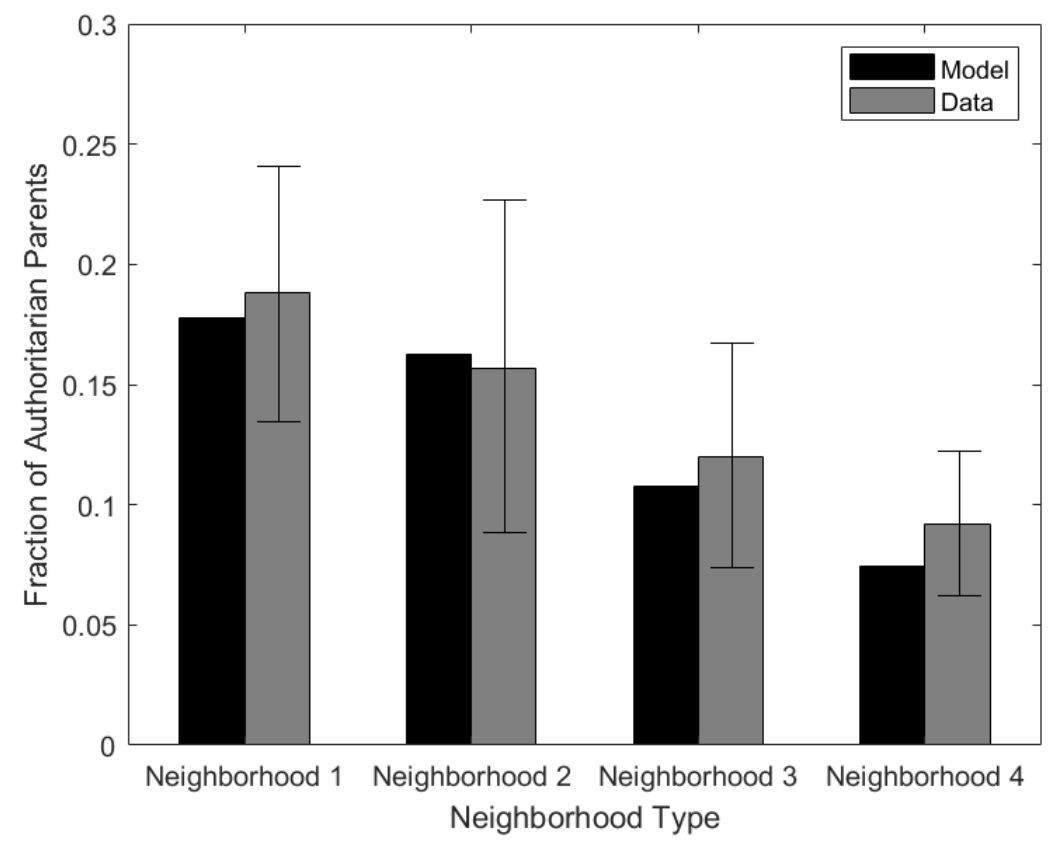

The figure shows the out-of-sample predictions of the model. The figure displays the fraction of authoritarian parents by neighborhood type as predicted by the model and as observed in the data. We calculate the model's predicted fraction of authoritarian parents as the average fraction among 50 different model simulations.

more advantaged neighborhoods. The model matches the data closely. In the poorest neighborhood, 18 percent of parents are authoritarian, while in the most affluent synthetic neighborhood this share is only 7 percent. In the model, the difference hinges on the estimated parameters of the skill formation technology. In high-quality neighborhoods, parents face better initial conditions in terms of both the peer environment and the skills of their own children. Because an authoritarian parenting style reduces the productivity of these inputs (by lowering total factor productivity and the effect of peers), the opportunity cost of authoritarian parenting is higher compared to poor neighborhoods, where parents are more focused on improving the child's peer group.

Figure 4 breaks down this result further by grade and neighborhood. Here, we see that in the two low-SES (socio-economic status) neighborhoods, the fraction of authoritarian parents declines as children advance through the grades, 
Figure 4: Out-of-Sample Fit: Parenting Style Dynamics and Neighborhood
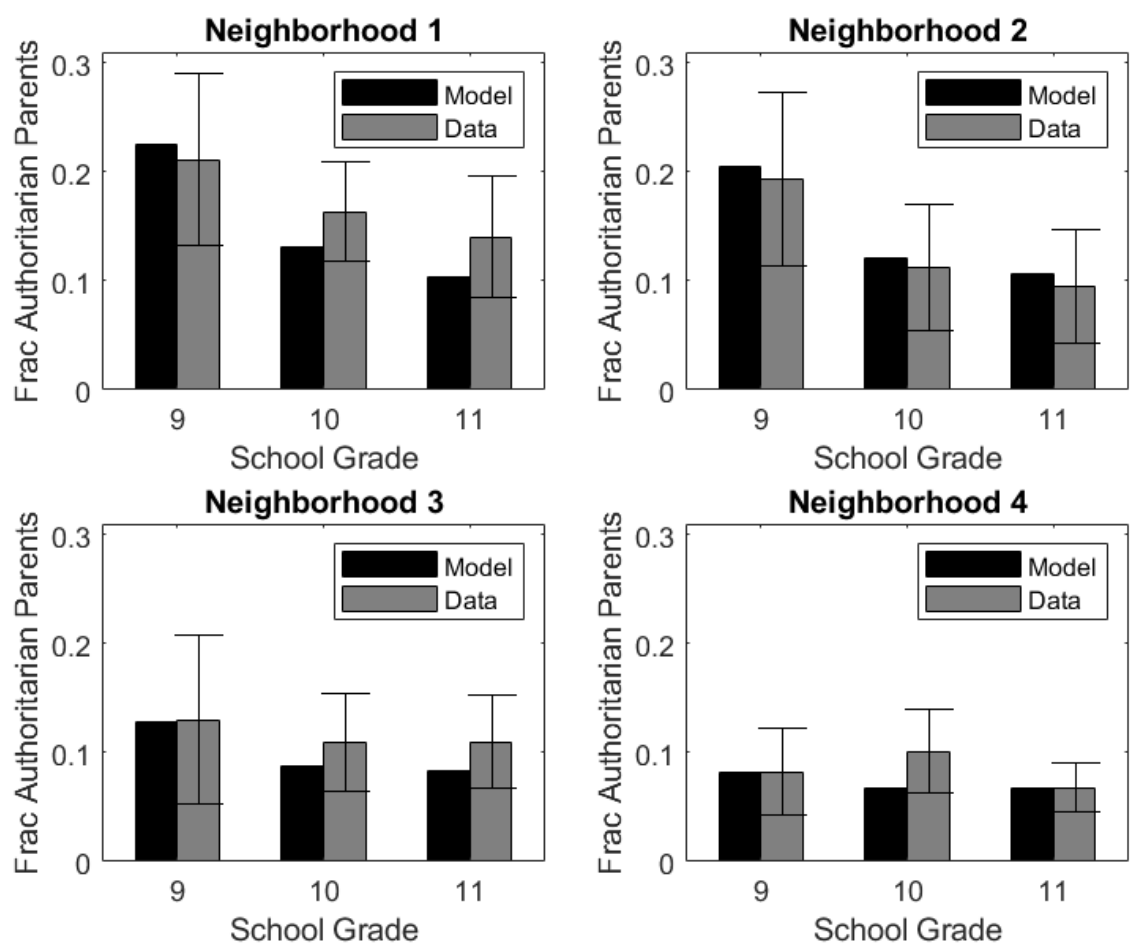

The figure shows the out-of-sample predictions of the model. The figure displays the fraction of authoritarian parents over school grades by neighborhood type as predicted by the model and as observed in the data. We calculate the model's predicted fraction of authoritarian parents as the average fraction among 50 different model simulations.

whereas the relationship is flat in the two high-SES neighborhoods. Once again, the estimated model fits these empirical observations well.

\section{Parents, Peers, and the Effect of Policy Interventions}

In this section, we study how parenting practices respond to policy interventions that change the peer environment. In particular, we run counterfactual policy experiments based on the estimated structural model. We consider two sets of experiments. The first is a "busing policy" that moves some children from a disadvantaged to a wealthy neighborhood. The second is a change in the initial conditions, which we interpret as resulting from interventions affecting children's skills before they start high school. 


\subsection{Busing Policy}

Consider a policy experiment moving children from the synthetic neighborhood with the second-lowest SES (henceforth, N2) to the synthetic neighborhood with the highest SES (henceforth, N4). Recall that the median family income of N2 is $\$ 48,000$, whereas that of $\mathrm{N} 4$ is $\$ 102,000$. These numbers compare to a national median family income of $\$ 58,000$ in 2016 , the year in which income is measured. The initial difference in children's mean skills between these neighborhoods is 0.87 standard deviations. We are interested in the individual treatment effect of being moved to a better neighborhood, the mechanisms behind this treatment effect, and how the treatment effect changes as the policy is scaled up to include more students.

Figure 5: Treatment Effects of Moving

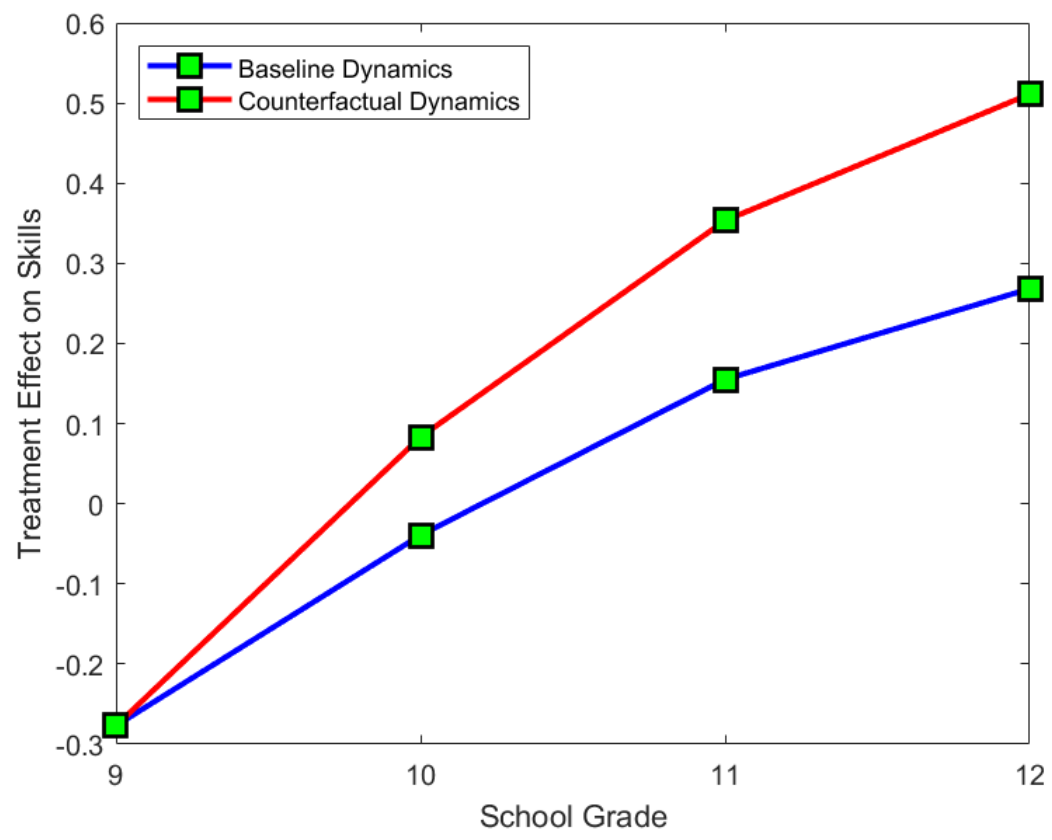

The figure shows the treatment effect on a child's skills of moving a child in 9th grade from N2 to N4. The blue line displays the baseline skills dynamics for the median child in the skills distribution in N2. The red line shows the counterfactual skills dynamics if the child is moved to $\mathrm{N} 4$ at the beginning of her 9th grade. The skill dynamics are calculated by averaging among 50 different model simulations.

Individual Treatment Effects: Figure 5 shows the dynamic treatment effect for 
a single child who is relocated from N2 to N4 when entering 9th grade. The blue line displays the average evolution of skills for a typical child staying in N2 throughout the high school years. The red line shows the counterfactual evolution of skills if the same child is moved to N4. The treatment effect starts showing up in 10th grade because skills are predetermined at the beginning of 9th grade. Subsequently, a growing gap opens up between the benchmark and counterfactual skills. The treatment effect increases over time because of the dynamic complementarity between skill accumulation and friendship formation. More concretely, the gain in skills accruing to the moved child in 10th grade has a positive effect on skill accumulation in the following periods and also improves the peer group the child is exposed to owing to the homophily bias in preferences.

To gauge the quantitative importance of the policy, we compare our treatment effect with the quasi-experimental evidence of Chyn (2018). Chyn studies the effect of a plausibly exogenous shock, namely public housing demolition, that forced many families to leave very poor neighborhoods in Chicago. Three years after demolition, the displaced families lived in neighborhoods with lower poverty and less violent crime compared to similar families who did not have to move. The children who moved out of the very poor neighborhoods earned on average $\$ 602$ more per year during their first adult years than those who stayed-a difference of 16 percent. In addition, displaced children had 14 percent fewer arrests for violent crimes and a significantly lower probability of dropping out of high school.

To compare the effect of moving one child from N2 to N4 in our model to Chyn's results, we perform the following back-of-the-envelope calculation. First, we convert differences in children's school performance into differences in earnings by regressing adult earnings in the Add Health data on our measure of skills during adolescence. Second, we note that according to our estimates, a child bused from N2 to N4 experiences an increases in skills equal to about 0.2 standard deviations. These two pieces of information imply that moving a child (in isolation) from N2 to N4 increases future annual earnings by about $\$ 900$ to $\$ 1,000$. $^{31}$

Our back-of-the-envelope calculation yields an effect that is 50 percent larger

\footnotetext{
${ }^{31}$ For comparability with Chyn (2018), we express monetary values in 2012 dollars.
} 
than the causal effect estimated by Chyn (2018). To account for the difference, recall that our busing policy moves children from a moderately poor neighborhood to the best available neighborhood in the economy. This change in neighborhood quality is larger than the typical experience of a child who was displaced by the public housing demolition. Furthermore, our monetization of the skill differences in Add Health is based on an empirical correlation of test scores and earnings that may be larger than the causal effect of test scores. With these caveats taken into account, the sizeable policy effects predicted by the model are in the ballpark of recent estimates of neighborhood effects in the literature.

Scaling Effects: Figure 5 refers to the case in which one child is moved in isolation from $\mathrm{N} 2$ to $\mathrm{N} 4$. If many children are moved together, the treatment effect changes, because the policy has a larger effect on the peer environment in N4. Figure 6 shows how the effect of busing children from N2 to N4 changes with the scale of the policy. The upper and lower panels show the effects for the children who are relocated and for those in the receiving community, respectively. A small-scale policy yields large gains for the moved children and very small effects on the receiving community. As the number of children increases, the positive effects for the moved children decline, while the negative effects for the receiving community increase. The differences are quantitatively large. When 40 children are moved together, the positive treatment effect on bused children is almost cut in half compared with the case of a single bused child. Moreover, the children in the wealthy neighborhood experience skill losses that are almost as large as the gains of the arriving ones. Given that there are more receiving children than new arrivals (there are initially 210 children in each school), the average effect on skill accumulation for all children involved (i.e., both moved and receiving children) turns negative as the policy is scaled up.

Multiple factors contribute to the deteriorating effect of the policy as it is scaled up. To start with, there is a mechanical dilution effect: as more children are relocated, the peer environment of the receiving neighborhood worsens. In addition, there are two more interesting endogenous mechanisms. The first is the endogenous peer group formation. In our model, lower-skill children are attractive as peers. This implies that as more low-skill children arrive, peer groups become 
Figure 6: Policy and Scaling Effects on Skills

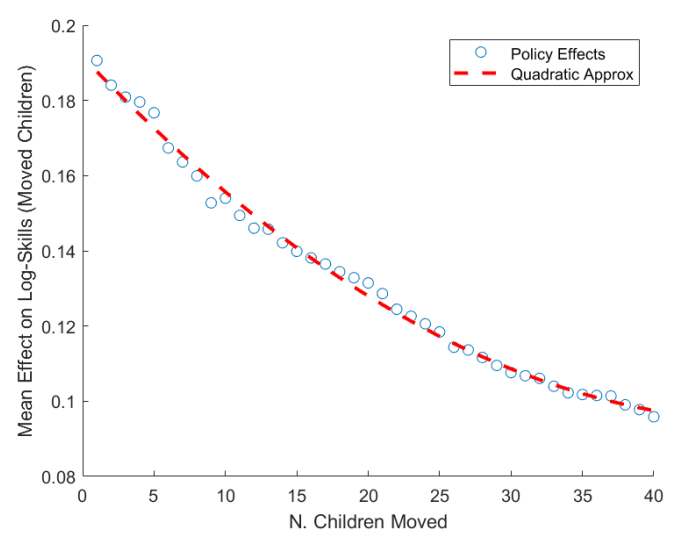

(a) Moved Children

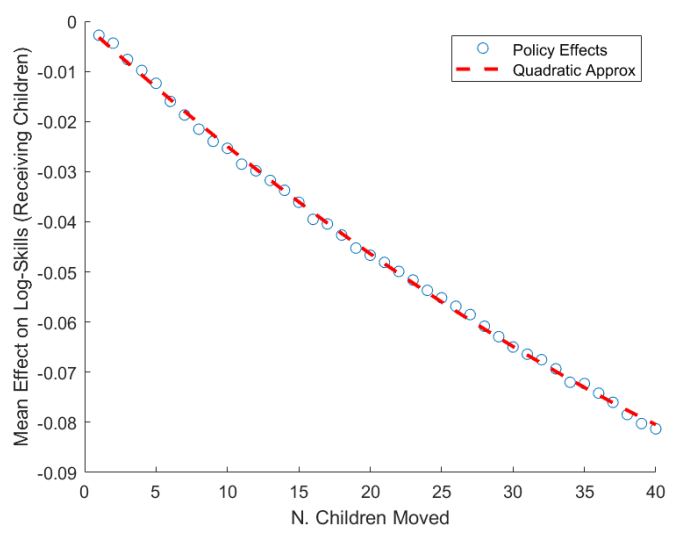

(b) Receiving Children

The figure shows the equilibrium policy effect on skills in 12th grade of moving children from N2 to N4 as a function of the number of moved children. Panel (a) illustrates the average effect for moved children. Panel (b) illustrates the average effect for receiving children. Each dot represents the average impact on skills for either moved children (Panel a) or receiving children (Panel b) for a given number of moved children. Each dot is calculated by averaging among 50 different model simulations.

disproportionately tilted toward them. In addition, because of the homophily bias, a large share of the bused children form ties with each other, thereby reducing the benefits from liaising with the high-skill children in the receiving community.

The second mechanism stems from the behavioral response of parents. Panels 
(a) and (b) of Figure 7 show how the parents of relocated children adjust their behavior as the scale of the program increases. If a single child moves from $\mathrm{N} 2$ to $\mathrm{N} 4$, the parent turns less authoritarian, which is a rational response to the more favorable peer group in N4. On its own, this shift in parenting style promotes skill accumulation. However, the authoritative investment of the nonauthoritarian parents decreases in response to the improved peer environment. Both of these effects fade away as more children are relocated to $\mathrm{N} 4$.

Panels (c) and (d) of Figure 7 show the response of parents in the host community. The scale of the policy increases the share of authoritarian parents. Intuitively, as more low-skill children arrive, parents in N4 increasingly worry about their own children befriending them, and more of them turn authoritarian. Other parents, especially those of the most proficient children, do not turn authoritarian but rather increase the time (authoritative) investments to compensate for the weaker peer environment. Both parental responses increase with the scale of the policy.

Both the homophily in peer-group-formation and the endogenous pushback of parents lead to more segregation as the policy is scaled up. In other words, as more children are bused, there is less mixing between the locals and the new arrivals.

The Importance of Endogenous Parenting Behavior: Given the presence of multiple channels, how important is the endogenous response of parents alone? To answer this question, we run alternative policy counterfactuals in which we hold parenting style fixed at the baseline level while allowing all other channels (dilution of the peer group and endogenous peer group formation) to operate. The results are shown in Figure 8. The upper panel compares the effect of the busing policy on the skill accumulation of the moved children with (blue dots) and without (red dots) an endogenous response in parenting. The gains would be substantially larger if parents did not change their behavior. A large share of this difference stems from the decline in authoritative investments. Bused children's parents who were already nonauthoritarian "slack off," i.e., spend less time with their children because their children now have better peers, and peer effects and time investments are substitutes. This effect is stronger when only a few children are moved because the peer environment in N4 is best in this case. An effect of 
Figure 7: Policy and Scaling Effects on Parental Behavior

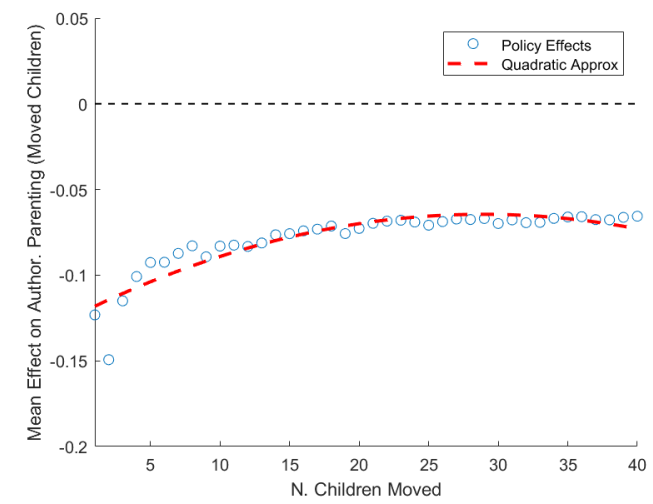

(a) Authoritarian (Moved)

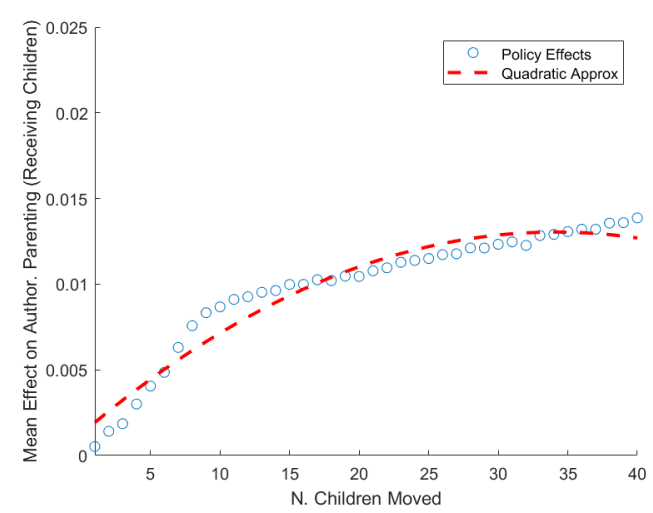

(c) Authoritarian (Receiving)

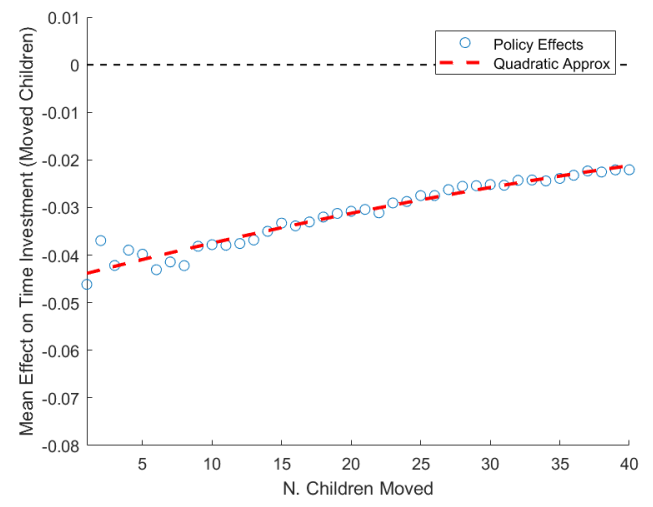

(b) Time Investment (Moved)

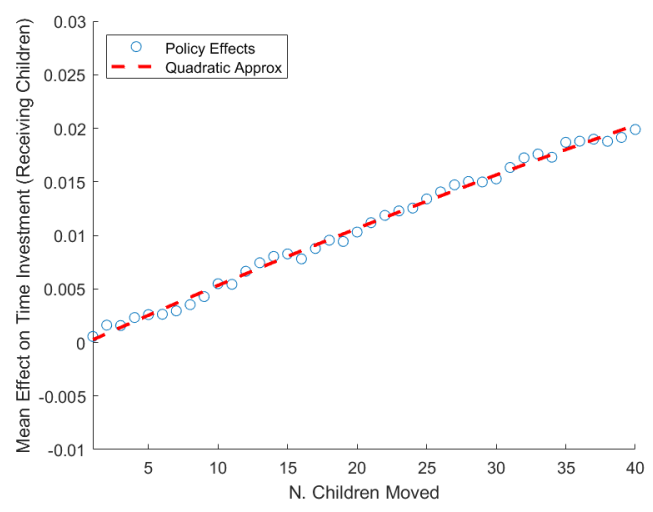

(d) Time Investment (Receiving)

The figure shows the equilibrium policy effect on the probability of being authoritarian (Panels (a) and (c)) and on parental time investment (Panels (b) and (d)) of moving children from N2 to N4 as a function of the number of moved children. Panels (a) and (b) illustrate the policy effect on parental behavior for moved children. Panels (c) and (d) illustrate the policy effect on parental behavior for receiving children. Each dot represents the average impact on parenting style or parental investments for either moved children (Panels (a) and (b)) or receiving children (Panels (c) and (d)) for a given number of moved children. Each dot is calculated by averaging among 50 different model simulations. 
Figure 8: Endogenous Parental Behavior and Policy Effects

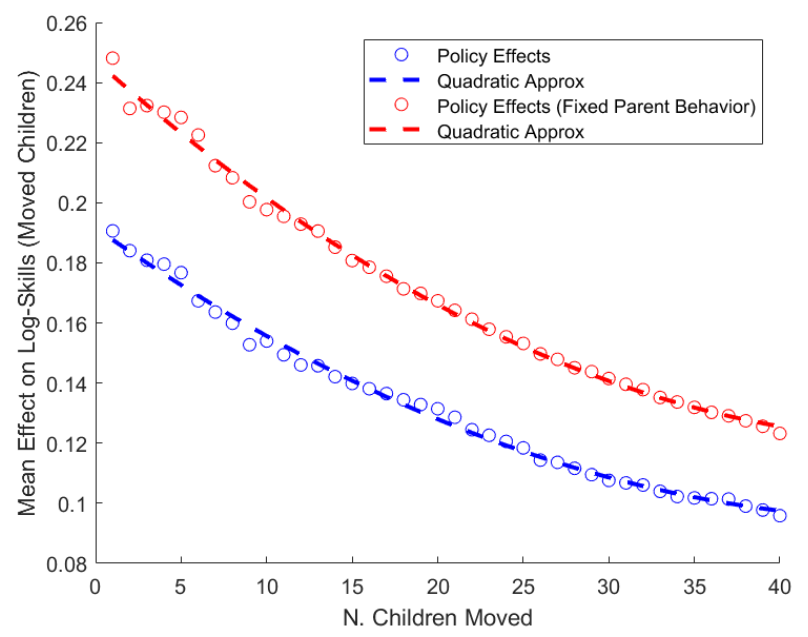

(a) Moved Children

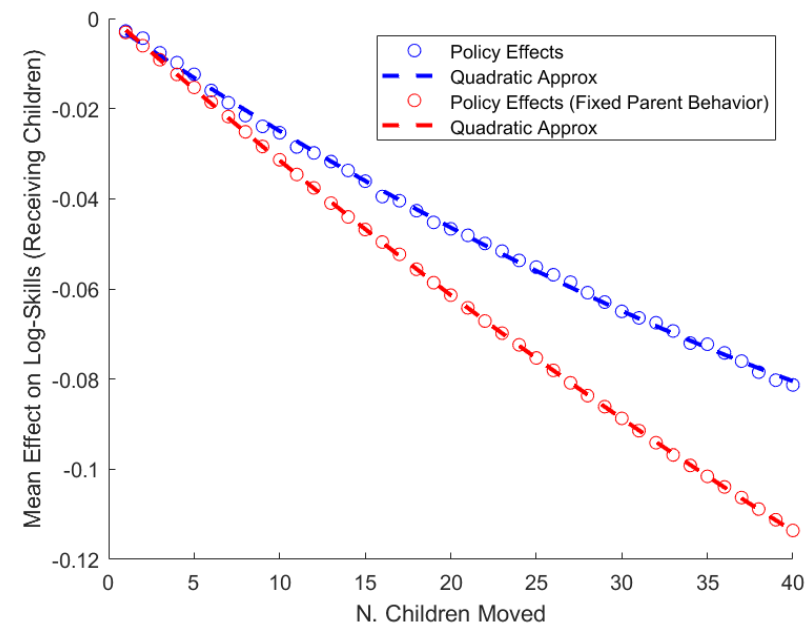

(b) Receiving Children

The figure shows the quantitative importance of the endogenous parental response for the counterfactual policy effects. The outcome is skills in 12th grade. The blue lines represent the equilibrium policy effects on skills in 12th grade of moving children from N2 to N4 as a function of the number of moved children (as in Figure 6). The red lines show the effect of the policy when parental behavior is held fixed. Panel (a) illustrates the effect for moved children. Panel (b) illustrates the effect for receiving children. Each dot represents the average impact on skills for a given number of moved children. Each dot is calculated by averaging among 50 different model simulations. 
the opposite sign is that fewer parents of the bused children behave in an authoritarian fashion, but this effect appears to be smaller. Finally, skill accumulation is adversely affected by the behavior of parents in the receiving community (more of them turn authoritarian).

The lower panel of the figure displays results for the skill accumulation of the children living in N4. Holding parenting behavior constant would increase skill losses, and more so as the program is scaled up. The parents of these children rationally protect them from a less favorable peer environment, at the expense of the poorer children. The quantitative effect is large: when 40 children are moved from N2 to N4, the change in parenting style of parents in N4 reduces the negative effect on their children's skill accumulation by about 30 percent.

\subsection{Changing Initial Conditions}

In this section, we study counterfactual changes in the initial distribution of skills, emphasizing different forms of reductions in inequality. We can interpret these experiments as interventions occurring before children reach high school, which range from early childhood education policies to targeted interventions in middle school.

Altering the initial distribution of skills will affect the process of friendship formation from the first period onward and will also affect skill formation through peer effects and endogenous parental responses. We evaluate the effect of these policies by comparing moments of the skill distribution in 12th grade.

The first column of Table 8 describes how we change initial conditions. The other columns report the effects (relative to the baseline) on the mean skill accumulation, on three measures of inequality (where the 10th percentile is reported to zoom in on poor families), and on parenting decisions. The table shows the aggregate effect (across all neighborhoods) and its breakdown into below- and above-median neighborhoods.

No Inequality. The first experiment equalizes the initial human capital of all students while keeping the national mean at the baseline level. Although there is no inequality in the first year, some differences materialize over time because 
Table 8: Counterfactual Policy Experiments: Changing Initial Conditions (e.g., Early Childhood Interventions)

\begin{tabular}{|c|c|c|c|c|c|c|}
\hline & (1) & $(2)$ & (3) & $(4)$ & (5) & (6) \\
\hline & \multicolumn{6}{|c|}{ Panel A: Aggregate } \\
\hline & Mean & 90-10 Ratio & 10th Percentile & Gini & Author Parenting & Time Inv \\
\hline No Inequality & $6.80 \%$ & $-40.90 \%$ & $43.33 \%$ & -0.11 & -0.06 & 0.07 \\
\hline No Between-Neighb. Inequality & $-4.23 \%$ & $-12.32 \%$ & $2.34 \%$ & -0.03 & 0.01 & 0.00 \\
\hline No Within-Neighb. Inequality & $10.94 \%$ & $-13.82 \%$ & $27.33 \%$ & -0.03 & -0.07 & 0.06 \\
\hline Truncate Local Distrib. at 10th percent & $8.32 \%$ & $-6.68 \%$ & $13.89 \%$ & -0.01 & -0.03 & 0.00 \\
\hline \multirow[t]{3}{*}{ Halving Cost of Parental Investments } & $27.45 \%$ & $10.39 \%$ & $19.17 \%$ & 0.02 & -0.03 & 0.16 \\
\hline & \multicolumn{6}{|c|}{ Panel B: Low-Income Neighborhood } \\
\hline & Mean & 90-10 Ratio & 10th Percentile & Gini & Author Parenting & Time Inv \\
\hline No Inequality & $29.63 \%$ & $-33.95 \%$ & $64.11 \%$ & -0.09 & -0.11 & 0.05 \\
\hline No Between-Neighb. Inequality & $15.91 \%$ & $-0.38 \%$ & $15.28 \%$ & -0.00 & -0.03 & -0.02 \\
\hline No Within-Neighb. Inequality & $7.40 \%$ & $-32.51 \%$ & $34.18 \%$ & -0.09 & -0.08 & 0.05 \\
\hline Truncate Local Distrib. at 10 th percent & $6.45 \%$ & $-11.20 \%$ & $14.96 \%$ & -0.03 & -0.04 & 0.01 \\
\hline \multirow[t]{3}{*}{ Halving Cost of Parental Investments } & $25.15 \%$ & $9.69 \%$ & $17.91 \%$ & 0.02 & -0.03 & 0.16 \\
\hline & \multicolumn{6}{|c|}{ Panel C: High-Income Neighborhood } \\
\hline & Mean & 90-10 Ratio & 10th Percentile & Gini & Author Parenting & Time Inv \\
\hline No Inequality & $-15.96 \%$ & $-19.29 \%$ & $-6.01 \%$ & -0.05 & 0.00 & 0.09 \\
\hline No Between-Neighb. Inequality & $-25.47 \%$ & $19.28 \%$ & $-33.32 \%$ & 0.04 & 0.08 & 0.02 \\
\hline No Within-Neighb. Inequality & $11.58 \%$ & $-19.85 \%$ & $25.19 \%$ & -0.05 & -0.03 & 0.04 \\
\hline Truncate Local Distrib. at 10th percent & $8.72 \%$ & $-8.23 \%$ & $14.63 \%$ & -0.02 & -0.02 & -0.01 \\
\hline Halving Cost of Parental Investments & $29.42 \%$ & $6.24 \%$ & $23.93 \%$ & 0.01 & -0.02 & 0.17 \\
\hline
\end{tabular}

random utility shocks lead to the formation of different peer networks. However, final inequality falls drastically short of the baseline, which is hardly surprising. More interestingly, equalizing opportunities increases the average skill accumulation-the gain in poor neighborhoods exceeds the loss in rich ones. This results stems, in part, from a decline in the popularity of the authoritarian parenting style in poor neighborhoods: the share of authoritarian parents drops from 17 to 9 percent. In the equal-opportunity society, parents cease to be worried about protecting their children from bad influences, which boosts the productivity of the skill formation technology (recall that an authoritarian parenting style is associated with lower total factor productivity). This effect is reinforced by a significant increase in authoritative parental investments across all neighborhoods. Authoritative investments increase in poor neighborhoods because parents stop being authoritarian. In previously rich neighborhoods, parents compensate for 
the worse peer environment by increasing their own time investment.

No Inequality Between Neighborhoods. The second experiment equalizes initial conditions across neighborhoods, setting inequality in each location equal to the nationwide level in the baseline economy. In other words, the overall inequality (measured by the variance of the log-normal distribution of skills) is unchanged, but all inequality is within neighborhoods. The policy can be interpreted as an eradication of residential segregation. Like in the first experiment, the policy increases skill accumulation in low-income neighborhoods and decreases it in high-income neighborhoods. However, the aggregate effect in terms of average skill accumulation is now negative. Although inequality declines, the gain for the families in the bottom decile is small. This might be surprising at first glance, given that disadvantaged children now live in more diverse neighborhoods where they can interact with strong peers. However, eliminating residential segregation does not guarantee that those children will actually form many friendships with high-skill peers. Both the homophily bias and the increasing number of authoritarian parents raise new barriers to the social integration of children of different initial skills.

No Inequality Within Neighborhoods. In the third experiment, we remove all within-neighborhood inequality while leaving intact the original inequality between neighborhoods. ${ }^{32}$ While the reduction in overall inequality is similar to the previous case, this experiment boosts the average skill accumulation more strongly. Average skills across the economy now increase, and the gains are especially large for families in the bottom decile, who enjoy a 27 percent gain relative to the baseline. Both the demise of the authoritarian parenting style and the increase in authoritative investments explain these results.

No Lower Tail Inequality. The fourth experiment consists of truncating the initial skill distribution at the 10th percentile within each neighborhood and redistributing the lower tail in proportion to the original distribution at each other

\footnotetext{
${ }^{32}$ Note that in this experiment total inequality declines because we do not compensate the reduction in within-neighborhood inequality by an increase between neighborhoods. If we do the compensation so as to hold total inequality at the same level as in the baseline, the average effect is still positive but highly asymmetric across rich and poor neighborhoods, which is largely driven by the artificial increase in between-neighborhood inequality.
} 
percentile. This can be interpreted as a form of early childhood intervention that targets the most-disadvantaged groups in each neighborhood's population. This policy generates larger average gains than those associated with shutting down inequality altogether. Although part of this gain accrues mechanically, the endogenous dynamics of skills and peers ensure that the gains are persistent and are even amplified over time. The policy triggers a significant decrease in the incidence of the authoritarian parenting style by about one quarter relative to the baseline. This counterfactual highlights an additional benefit of early childhood interventions that has not been captured by past research: by reducing the share of "problematic" low-skill peers in the population, the policy makes parenting more relaxed overall, which reduces the barriers faced by the more disadvantaged children and improves skill formation.

Subsidy to Time-Intensive Parental Investments. Finally, we consider a policy that reduces the cost of authoritative investments. The size of the policy is such that the investment cost halves, resulting in an increase of investment by 16 percentage points (the investment variable ranges between 0 and 1 with an average of 0.33 ). The effects of the policy are beneficial across the board. While a large part of the gains stem from higher parental investments, there is also a shift in parenting styles, with a reduction in the share of authoritarian parents by $2-3$ percentage points.

Across all the policies considered, we find that endogenous parental responses play an important role in shaping the effects of the intervention. There is a particularly high upside to interventions that reduce local inequality. Such policies improve the peer environment and thereby reduce the share of parents that adopt an authoritarian style. This shift in parenting has a direct positive impact on skill accumulation (through productivity) and additional benefits for inequality because it promotes interactions between peers from different backgrounds.

\section{Conclusions}

In this paper, we examine the effect of parenting style on the skill formation of children during the high school years. This is a phase when peers increasingly replace parents as the most important influence on children. Nevertheless, we 
argue that parents continue to play an important role, in significant part because of their influence on their children's peer formation, i.e., on who their children's friends are.

We capture the mutual interactions between children, parents, and peers by constructing and estimating a dynamic rational choice model of skill formation with endogenous peer effects. In the model, children choose who to be friends with. Parents can choose whether to intervene in their child's choice of friends by discouraging friendships with low-skill peers. We interpret the choice to interfere in peer formation as adopting an authoritarian parenting style. This choice of parenting style involves a tradeoff: while an authoritarian parenting style can improve the quality of the child's peer group, the interference jeopardizes a harmonious family life and may make the child less receptive to other forms of parental investments. Indeed, our estimation implies that authoritarian parenting reduces the productivity of the technology of skill formation. As a result, parents adopting a nonauthoritarian style give up on directly influencing their child's selection of friends, but are more effective at fostering their children's skill formation through other time investments.

The choice of parenting style hinges on the peer environment that children face. In an affluent and homogeneous neighborhood, parents have little reason to be concerned about their children's peer selection, and are likely to adopt a nonauthoritarian style. In contrast, in low-income and unequal neighborhoods where there is high exposure to the influence of disruptive peers, parents are more likely to choose to be authoritarian. This is particularly true for parents of children who themselves have relatively low skills, because such children (given homophily bias in peer preferences) are especially likely to associate with low-skill peers.

The model is estimated using an indirect inference approach that exploits variation in skills and peers within school and grades. The estimated model provides a good out-of-sample fit across neighborhoods with different socio-economic characteristics.

We use the estimated model to evaluate the impact of a counterfactual busing policy whereby children from a low-SES neighborhood are moved to a school in an affluent area. Our model is well-suited to study how the benefits of the 
policy change as it is scaled up, i.e., many disadvantaged children are moved to a better school at the same time. We find that scaling up substantially lowers the treatment effect: when 40 children instead of a single child are moved, the improvement in the moved children's skills is almost cut in half. A significant part of the treatment effect stems from endogenous parental behavior. As more children are moved, more parents in the affluent host community adopt an authoritarian parenting style and discourage their own children from befriending the new arrivals. This defensive response reduces the benefits of the policy as it is scaled up.

The conclusions of our study raise broader questions about the interpretation of reduced-form estimates of neighborhood effects (e.g., Chetty, Hendren, and Katz 2016). When a single family moves to a better neighborhood, the children may indeed enjoy large gains, in part because of better peer effects. However, larger-scale policies such as building social housing in affluent areas can trigger reactions that limit their effectiveness. Our analysis highlights two types of barriers that might emerge as the scale of a policy intervention grows. The first is homophily bias in children's preferences. Residential proximity does not guarantee that children from different socio-economic status will mingle with each other and form friendships. The second is endogenous parenting decisions. When a large number of children are moved from disadvantaged areas into an affluent community, local parents may start to actively discourage their children from mixing with the newcomers.

The common thread across all policy experiments we consider is that the two forces of endogenous peer group formation and endogenous parenting behavior have a substantial impact on outcomes. This is also apparent when we study the effect of policies that reduce skill inequality before children enter high school. Policies that increase the heterogeneity of peer groups tend to reinforce segregation, driven both by homophily bias in children's preferences and by an increase in authoritarian parenting. The result of a counterfactual experiment in which we remove residential segregation entirely is a testimony to the challenge of promoting integration. This policy has a negative effect on average skill accumulation and limited benefits even for children in the bottom decile of the skill 
distribution. In contrast, policies that curb lower-tail local inequality are promising. Generally, successful policies work at least in part through a reduction in the popularity of the authoritarian parenting style.

Our analysis does not consider a variety of aspects that may be important in reality. We have no information on residential choice before children start high school. We also do not emphasize heterogeneity in the quality of parental inputs across families. The data show, for instance, that parenting style has heterogeneous effects across intact and single-parent family environments. Also, our data are from the 1990s. New technologies may affect the structure of social interaction across children as well as the effect of parents' interference with the process of skill formation. Another limitation is that we proxy peer effects by the average quality of friends. The dynamics of children's networks are clearly more complex and worth a more thorough investigation. In spite of these and other limitations, our paper provides a first theory- and data-driven exploration of the dynamic interaction between parenting, children's decisions, and society in the process of skill formation of teenagers.

\section{References}

Agostinelli, Francesco. 2018. "Investing in Children's Skills: An Equilibrium Analysis of Social Interactions and Parental Investments." Unpublished Manuscript, University of Pennsylvania.

Agostinelli, Francesco, and Giuseppe Sorrenti. 2018. "Money vs. Time: Family Income, Maternal Labor Supply, and Child Development." HCEO Working Paper 2018-017.

Agostinelli, Francesco, and Matthew Wiswall. 2016. "Estimating the Technology of Children's Skill Formation." NBER Working Paper 22442.

Akabayashi, Hideo. 2006. "An Equilibrium Model of Child Maltreatment." Journal of Economic Dynamics and Control 30 (6): 993-1025.

Almlund, M., A. Duckworth, J. J. Heckman, and T. Kautz. 2011. “Personality Psychology and Economics." In Handbook of the Economics of Education, Vol. 4, edited by E. A. Hanushek, S. Machin, and L. Woessmann. Amsterdam: Elsevier. 
Altonji, Joseph G., and Richard K. Mansfield. 2018. "Estimating Group Effects Using Averages of Observables to Control for Sorting on Unobservables: School and Neighborhood Effects." American Economic Review 108 (10): 2902-46.

Angrist, Joshua D., and Kevin Lang. 2004. "Does School Integration Generate Peer Effects? Evidence from Boston's Metco Program." American Economic Review 94 (5): 1613-34.

Arcidiacono, Peter, Gigi Foster, Natalie Goodpaster, and Josh Kinsler. 2012. "Estimating Spillovers Using Panel Data, with an Application to the Classroom." Quantitative Economics 3 (3): 421-70.

Attanasio, Orazio. 2015. "The Determinants of Human Capital Formation During the Early Years of Life: Theory, Measurement, and Polices." Journal of the European Economic Association 13 (6): 949-97.

Attanasio, Orazio, Sarah Cattan, Emla Fitzsimons, Costas Meghir, and Marta Rubio-Codina. 2020. "Estimating the Production Function for Human Capital: Results from a Randomized Control Trial in Colombia." American Economic Review 110 (1): 489-85.

Attanasio, Orazio, Costas Meghir, and Emily Nix. 2019. "Human Capital Development and Parental Investment in India." NBER Working Paper 21740.

Badev, Anton. 2016. "Discrete Games in Endogenous Networks: Theory and Policy." Unpublished Manuscript, University of Pennsylvania.

Baumrind, Diana. 1967. "Child Care Practices Anteceding Three Patterns of Preschool Behavior." Genetic Psychology Monographs 75 (1): 43-88.

Bifulco, Robert, Jason M. Fletcher, and Stephen L. Ross. 2011. “The Effect of Classmate Characteristics on Post-Secondary Outcomes: Evidence from the Add Health." American Economic Journal: Economic Policy 3 (1): 25-53.

Blume, Lawrence E., William A. Brock, Steven N. Durlauf, and Rajshri Jayaraman. 2015. "Linear Social Interactions Models." Journal of Political Economy 123 (2): 444-96.

Blume, Lawrence E., L. E., W. A. Brock, S.N. Durlauf, and Y. M. Ioannides. 2011. "Identification of Social Interactions." In Handbook of Social Economics, edited 
by J. Benhabib, A. Bisin, and M. O. Jackson, Volume 1, 853-964. Amsterdam: Elsevier.

Brenøe, Anne Ardila, and Thomas Epper. 2019. "Parenting Values and the Intergenerational Transmission of Time Preferences." Unpublished Manuscript, University of St. Gallen.

Brock, William A., and S. N. Durlauf. 2001a. "Interactions-Based Models." In Handbook of Econometrics, edited by J. J. Heckman and E. E. Leamer, Volume 5, 3297-380. Amsterdam: Elsevier.

Brock, William A., and Steven N. Durlauf. 2001b. "Discrete Choice with Social Interactions." Review of Economic Studies 68 (2): 235-60.

_. 2002. "A Multinomial-Choice Model of Neighborhood Effects." American Economic Review 92 (2): 298-303.

Brooks, Jane. 2013. The Process of Parenting. New York: McGraw-Hill.

Calvó-Armengol, Antoni, Eleonora Patacchini, and Yves Zenou. 2009. "Peer Effects and Social Networks in Education." Review of Economic Studies 76 (4): $1239-67$.

Carrell, Scott E., Bruce I. Sacerdote, and James E. West. 2013. “From Natural Variation to Optimal Policy? The Importance of Endogenous Peer Group Formation." Econometrica 81 (3): 855-82.

Case, A., and L. F. Katz. 1991. "The Company You Keep: The Effects of Family and Neighborhood on Disadvantaged Youths." NBER Working Paper 3705.

Chetty, Raj, and Nathaniel Hendren. 2018a. "The Impacts of Neighborhoods on Intergenerational Mobility I: Childhood Exposure Effects." Quarterly Journal of Economics 133 (3): 1107-62.

_. 2018b. "The Impacts of Neighborhoods on Intergenerational Mobility II: County-Level Estimates." Quarterly Journal of Economics 133 (3): 1163-228. Chetty, Raj, Nathaniel Hendren, and Lawrence F. Katz. 2016. “The Effects of Exposure to Better Neighborhoods on Children: New Evidence from the Moving to Opportunity Experiment." American Economic Review 106 (4): 855-902. 
Chetty, Raj, Nathaniel Hendren, Patrick Kline, and Emmanuel Saez. 2014. "Where is the Land of Opportunity? The Geography of Intergenerational Mobility in the United States." Quarterly Journal of Economics 129 (4): 1553623.

Chyn, Eric. 2018. "Moved to Opportunity: The Long-Run Effects of Public Housing Demolition on Children." American Economic Review 108 (10): 302856.

Cobb-Clark, Deborah A., Nicolas Salamanca, and Anna Zhu. 2019. "Parenting Style as an Investment in Human Development." Journal of Population Economics 32 (4): 1315-52.

Cunha, Flavio, and James J. Heckman. 2007. “The Technology of Skill Formation." American Economic Review 97 (2): 31-47.

_. 2008. "Formulating, Identifying and Estimating the Technology of Cognitive and Noncognitive Skill Formation." Journal of Human Resources 43 (4): 738-82.

Cunha, Flavio, James J. Heckman, and Susanne M. Schennach. 2010. “Estimating the Technology of Cognitive and Noncognitive Skill Formation." Econometrica 78 (3): 883-931.

Currarini, Sergio, Matthew Jackson, and Paolo Pin. 2009. "An Economic Model of Friendship: Homophily, Minorities and Segregation." Econometrica 77 (4): 1003-45.

Cutler, David M., and Edward L. Glaeser. 1997. "Are Ghettos Good or Bad?" Quarterly Journal of Economics 112 (3): 827-72.

Dahl, Gordon B., and Lance Lochner. 2012. “The Impact of Family Income on Child Achievement: Evidence from the Earned Income Tax Credit." American Economic Review 102 (5): 1927-56.

Del Boca, Daniela, Christopher Flinn, Ewout Verriest, and Matthew J. Wiswall. 2019. "Actors in the Child Development Process." Unpublished Manuscript, University of Wisconsin.

Del Boca, Daniela, Christopher Flinn, and Matthew Wiswall. 2014. "Household Choices and Child Development." Review of Economic Studies 81 (1): 137-85. 
Doepke, Matthias, Giuseppe Sorrenti, and Fabrizio Zilibotti. 2019. “The Economics of Parenting." Annual Review of Economics 11:55-84.

Doepke, Matthias, and Fabrizio Zilibotti. 2017. "Parenting with Style: Altruism and Paternalism in Intergenerational Preference Transmission." Econometrica 85 (5): 1331-71.

- 2019. Love, Money, and Parenting: How Economics Explains the Way We Raise Our Kids. Princeton, New Jersey: Princeton University Press.

Durlauf, Steven N. 2004. "Neighborhood Effects." In Cities and Geography, edited by Henderson J. Vernon and Jacques-François Thisse, Volume 4 of Handbook of Regional and Urban Economics, 2173-242. Elsevier.

Durlauf, Steven N., and Yannis M. Ioannides. 2010. "Social Interactions." Annual Review of Economics 2 (1): 451-78.

Eckert, Fabian, and Tatjana Kleineberg. 2019. "Can We Save the American Dream? A Dynamic General Equilibrium Analysis of the Effects of School Financing on Local Opportunities." Unpublished Manuscript, Yale University.

Feld, Jan, and Ulf Zölitz. 2017. "Understanding Peer Effects: On the Nature, Estimation, and Channels of Peer Effects." Journal of Labor Economics 35 (2): 387-428.

Fogli, Alessandra, and Veronica Guerrieri. 2018. "The End of the American Dream? Inequality and Segregation in US Cities." Unpublished Manuscript, University of Chicago.

Harris, Judith Rich. 1998. The Nurture Assumption: Why Children Turn Out the Way They Do. Free Press.

Heckman, James J., and Stefano Mosso. 2014. "The Economics of Human Development and Social Mobility." Annual Review of Economics 6 (1): 689-733.

Heckman, James J., Rodrigo Pinto, and Peter A. Savelyev. 2013. “Understanding the Mechanisms through Which an Influential Early Childhood Program Boosted Adult Outcomes." American Economic Review 103 (6): 2052-86. 
Heckman, James J., Jora Stixrud, and Sergio Urzua. 2006. "The Effects of Cognitive and Noncognitive Abilities on Labor Market Outcomes and Social Behavior." Journal of Labor Economics 24 (3): 411-82.

Hoxby, Caroline. 2000. "Peer Effects in the Classroom: Learning from Gender and Race Variation." NBER Working Paper 7867.

Jackson, Matthew. 2010. Social and Economic Networks. Princeton University Press.

Jencks, Christopher, and Susan E. Mayer. 1990. "The Social Consequences of Growing Up in a Poor Neighborhood." In Inner-City Poverty in the United States, edited by E. Lynn Laurence Jr. and Michael G. H. McGeary, 111-185. Washington, DC: National Academies Press.

Kim, Jun Hyung. 2019. "The Economics of Parenting Skill and Child Development." Unpublished Manuscript, Jinan University.

List, John, Fatemeh Momeni, and Yves Zenou. 2019. “Are Estimates of Early Education Programs Too Pessimistic? Evidence from a Large-Scale Field Experiment that Causally Measures Neighbor Effects." CEPR Discussion Paper 13725.

Lizzeri, Alessandro, and Marciano Siniscalchi. 2008. "Parental Guidance and Supervised Learning." Quarterly Journal of Economics 123 (3): 1161-95.

Løken, Katrine V., Magne Mogstad, and Matthew Wiswall. 2012. "What Linear Estimators Miss: The Effects of Family Income on Child Outcomes." American Economic Journal: Applied Economics 4 (2): 1-35.

McPherson, Miller, Lynn Smith-Lovin, and James Cook. 2001. "Birds of a Feather: Homophily in Social Networks." Annual Review of Sociology 27:41544.

Mele, Angelo. 2019. “Does School Desegregation Promote Diverse Interactions? An Equilibrium Model of Segregation Within Schools." Unpublished Manuscript, Johns Hopkins Carey Business School.

Olivetti, Claudia, Eleonora Patacchini, and Yves Zenou. 2020. "Mothers, Peers, and Gender-Role Identity." Journal of the European Economic Association 18 (1): 266-301. 
Özdemir, Yasemin. 2019. "Parental Investment and Peer Effects in Cognitive and Non-Cognitive Skills." Unpublished Manuscript, University of Mannheim.

Patacchini, Eleonora, and Yves Zenou. 2011. "Neighborhood Effects and Parental Involvement in the Intergenerational Transmission of Education." Journal of Regional Science 51 (5): 987-1013.

Sacerdote, Bruce. 2001. "Peer Effects with Random Assignment: Results for Dartmouth Roommates." Quarterly Journal of Economics 116 (2): 681-704.

_ 2011. "Peer Effects in Education: How Might They Work, How Big Are They and How Much Do We Know Thus Far?" In Handbook of the Economics of Education, edited by Eric A. Hanushek, Stephen Machin, and Ludger Woessman, Volume 3, 249-77. Amsterdam: Elsevier.

Sampson, Robert J., Jeffrey D. Morenoff, and Thomas Gannon-Rowley. 2002. "Assessing "Neighborhood Effects": Social Processes and New Directions in Research." Annual Review of Sociology 28 (1): 443-78.

Tamayo Castano, Jorge Andres. 2016. “The Impact of Peer Effects on Student Outcomes: Evidence from Colombia." Unpublished Manuscript, University of Southern California.

Todd, Petra E., and Kenneth I. Wolpin. 2003. "On the Specification and Estimation of the Production Function for Cognitive Achievement." Economic Journal 113 (485): F3-F33.

- 2007. "The Production of Cognitive Achievement in Children: Home, School, and Racial Test Score Gaps." Journal of Human Capital 1 (1): 91-136.

Weinberg, Bruce A. 2001. "An Incentive Model of the Effect of Parental Income on Children." Journal of Political Economy 109 (2): 266-80.

Zimmerman, David. 2003. "Peer Effects in Academic Outcomes: Evidence from a Natural Experiment." The Review of Economics and Statistics 85 (02): 9-23.

Zumbuehl, Maria, Thomas Dohmen, and Gerard Pfann. 2018. "Parental Involvement and the Intergenerational Transmission of Economic Preferences and Attitudes." The Swiss Leading House on Economics of Education, Firm Behavior and Training Policies Working Paper 148. 


\section{Appendices}

\section{A Additional Figures and Tables}

This section provides additional figures and tables aimed at complementing the empirical analysis of the paper.

Figure A-1 shows the correlation between parenting styles and neighborhood quality. The definition of parenting styles mirrors the one in Doepke and Zilibotti (2017) and is based on the answer parents give to the question: "Of the following, which do you think is the most important thing for a boy/girl to learn? Be well-behaved, work hard, think for himself, help others, be popular." We define authoritarian parents as those who choose "be well-behaved," authoritative parents as those opting for "work hard," and permissive parents as those who choose "think for themselves." Neighborhood quality is defined as the median family income in the school attended by the child (left panels), or as the 90-10 ratio for family income at the school level (right panels).

Table A- 1 shows the summary statistics for the variables used in the empirical analysis.

Table A-2 replicates the analysis of the effect of neighborhood quality on authoritarian parenting by using the within-school within-grade GPA Gini coefficient as the measure for inequality.

Tables A-3 through A-6 show the sample fit of the model. Table A-3 reports the sample fit for the estimates of a linear probability model of authoritarian parenting style on a child's and peers' skills. Table A-4 focuses on the linear regression model of a child's next-period skills on current skills, peers' skills, and authoritarian parenting style. Table A-5 shows the estimates for the regression of the next-period average peers' skills on the child's current period skills, peers' skills, and authoritarian parenting style. Finally, Table A-6 reports the estimates for regressions of authoritative parental investments on the child's current period skills and peers' skills, with a breakdown between authoritarian and nonauthoritarian parents. 
Figure A-1: Parenting Style and Neighborhood Quality
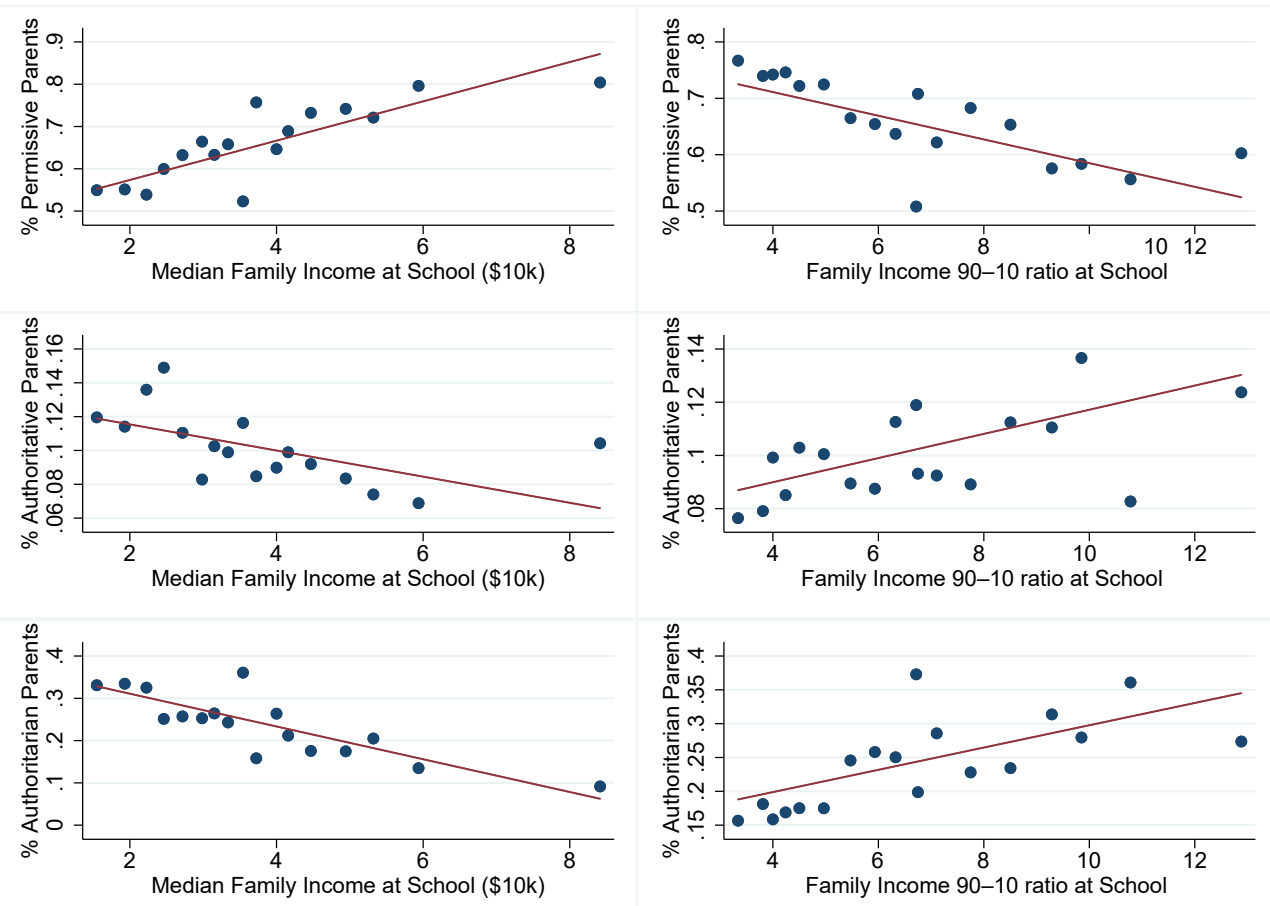

The figure shows how the incidence of the three parenting styles (permissive, authoritative, and authoritarian) varies with within-school average family income (left panel) and inequality (right panel). The measure of parenting style follows Doepke and Zilibotti (2017) and is discussed in the text. Inequality is measured by the 90th-10th percentile ratio of within-school family income. The top, central, and bottom panel show the incidence of permissive, authoritative, and authoritarian parenting style, respectively. 
Table A-1: Sample Statistics

\begin{tabular}{|c|c|c|c|}
\hline & \multicolumn{3}{|c|}{ Wave I: In-School Inteview } \\
\hline & Mean & SD & Obs \\
\hline English Grade & 2.84 & 0.97 & 38,300 \\
\hline Math Grade & 2.71 & 1.03 & 38,300 \\
\hline History Grade & 2.89 & 0.99 & 38,300 \\
\hline Science Grade & 2.81 & 1.01 & 38,300 \\
\hline Child's GPA & 2.81 & 0.78 & 38,300 \\
\hline \multirow[t]{3}{*}{$\mathrm{N}$ of Schools } & 66 & & \\
\hline & \multicolumn{3}{|c|}{ Wave I: In-Home Inteview } \\
\hline & Mean & $\mathrm{SD}$ & Obs \\
\hline Real family income (in 2016 US dollars) & 75,544 & 81,151 & 7,685 \\
\hline Talked with your mom about a party you attended & 0.52 & 0.50 & 9,627 \\
\hline Talked with your mom about a personal problem & 0.41 & 0.49 & 9,627 \\
\hline Worked with your mom on a project for school & 0.11 & 0.31 & 9,627 \\
\hline Do your parents let you choose your own friends? & 0.13 & 0.34 & 10,057 \\
\hline \multirow[t]{3}{*}{ PPVT Score } & 66.16 & 11.13 & 9,838 \\
\hline & \multicolumn{3}{|c|}{ Wave II } \\
\hline & Mean & $\mathrm{SD}$ & Obs \\
\hline English Grade & 2.89 & 0.93 & 3,744 \\
\hline Math Grade & 2.70 & 1.02 & 3,744 \\
\hline History Grade & 2.94 & 0.97 & 3,744 \\
\hline Science Grade & 2.86 & 0.98 & 3,744 \\
\hline
\end{tabular}

The table shows some summary statistics for the variables and sample used in our estimation. Note that we restrict the original sample in Add Health to high schools with at least 200 children and to cohorts with at least 100 students. 
Table A-2: Authoritarian Parenting and Neighborhood Quality

\begin{tabular}{|c|c|c|c|c|c|c|}
\hline & \multicolumn{6}{|c|}{ Authoritarian } \\
\hline & (1) & $(2)$ & (3) & $(4)$ & (5) & (6) \\
\hline \multirow[t]{2}{*}{ Mean GPA within Grade } & $-0.114^{* *}$ & & 0.025 & -0.059 & & 0.025 \\
\hline & $(0.046)$ & & $(0.056)$ & $(0.042)$ & & $(0.052)$ \\
\hline \multirow[t]{2}{*}{ Gini GPA within Grade } & & $0.032^{* * *}$ & $0.036^{* * *}$ & & $0.021^{* *}$ & $0.025^{* *}$ \\
\hline & & $(0.008)$ & $(0.011)$ & & $(0.009)$ & $(0.011)$ \\
\hline Mean Dep & 0.130 & 0.130 & 0.130 & 0.130 & 0.130 & 0.130 \\
\hline Obs & 10057 & 10057 & 10057 & 10057 & 10057 & 10057 \\
\hline Clusters & 63 & 63 & 63 & 63 & 63 & 63 \\
\hline Controls & No & No & No & Yes & Yes & Yes \\
\hline School F.E. & Yes & Yes & Yes & Yes & Yes & Yes \\
\hline
\end{tabular}

The table shows the estimated coefficients of regressions whose dependent variable is an indicator variable for authoritarian parenting at the individual level. The Gini GPA grade is the Gini coefficient for GPA at the school and grade level. All models include school fixed effects. The regressions include mother's education, family income, and child's race, age, and gender as control variables. Standard errors are clustered at the school level. 
Table A-3: Sample Fit of the Model: Parenting Style

\begin{tabular}{lcc}
\hline \hline & & \\
& \multicolumn{2}{c}{ Authoritarian } \\
\cline { 2 - 3 } & $(1)$ & $(2)$ \\
& Model & Data \\
\hline Child's Skills & -0.075 & -0.016 \\
Peer Skills & -0.021 & -0.017 \\
\hline Mean Dep. Variable & 0.135 & 0.140 \\
\hline \hline
\end{tabular}

The table shows the sample fit for the estimates of a linear probability model of authoritarian style on a child's skills and on the peer's skills. Column (1) displays the estimates generated from the simulated model. Column (2) shows the estimates from the data. We calculate the model's predicted coefficients by averaging among 50 different model simulations.

Table A-4: Sample Fit of the Model: Skill Accumulation

\begin{tabular}{lcccccc}
\hline \hline & \multicolumn{7}{c}{ Next-Period Skills } \\
& \multicolumn{7}{c}{ Pooled Sample } & Authoritarian = & Authoritarian = 1 \\
\cline { 2 - 7 } & $(1)$ & $(2)$ & $(3)$ & $(4)$ & $(5)$ & $(6)$ \\
& Model & Data & Model & Data & Model & Data \\
\hline Child's Skills & 0.889 & 0.823 & 0.917 & 0.835 & 0.776 & 0.650 \\
Peer Skills & 0.316 & 0.144 & 0.332 & 0.129 & 0.194 & 0.212 \\
Authoritarian & -0.048 & 0.047 & & & & \\
\hline Mean Child's Skills (Grade 9) & -0.039 & -0.017 & & & & \\
Mean Child's Skills (Grade 10) & 0.053 & 0.082 & & & & \\
Mean Child's Skills (Grade 11) & 0.204 & 0.130 & & & & \\
Mean Child's Skills (Grade 12) & 0.313 & 0.341 & & & & \\
\hline \hline
\end{tabular}

The table shows the estimates for a linear regression model of the next-period child's skills on the current period child's skills, peer's skills, and parenting style. Odd columns display the estimates generated from the simulated model. Even columns show the estimates from the data. We calculate the model's predicted coefficients by averaging among 50 different model simulations. 
Table A-5: Sample Fit of the Model: Peer Skills

\begin{tabular}{lcccccc}
\hline \hline & \multicolumn{7}{c}{ Next Period Peer Skills } \\
& \multicolumn{7}{c}{ Pooled Sample } & Authoritarian $=0$ & Authoritarian = 1 \\
\cline { 2 - 7 } & $(1)$ & $(2)$ & $(3)$ & $(4)$ & $(5)$ & $(6)$ \\
& Model & Data & Model & Data & Model & Data \\
\hline Child's Skills & 0.283 & 0.223 & 0.277 & 0.223 & 0.321 & 0.152 \\
Peer Skills & 0.179 & 0.314 & 0.183 & 0.327 & 0.149 & 0.248 \\
Authoritarian & 0.070 & 0.012 & & & & \\
\hline Mean Number of Friends & 6.812 & 6.935 & & & & \\
\hline \hline
\end{tabular}

The table shows the estimates for a linear regression model of next-period average skill of peers on current period child's skills, peer's skills, and parenting style. Odd columns display the estimates generated from the simulated model. Even columns show the estimates from the data. We calculate the model's predicted coefficients by averaging among 50 different model simulations.

Table A-6: Sample Fit of the Model: Parental Investments

\section{Parental Investments}

Authoritarian $=0 \quad$ Authoritarian $=1$

(1) (2) (3) (4)

\begin{tabular}{lcccc} 
& Model & Data & Model & Data \\
\hline Child's Skills & 0.153 & 0.114 & 0.003 & 0.035 \\
Peer Skills & -0.093 & -0.065 & 0.002 & 0.028 \\
\hline Mean Dep. Variable & 0.028 & 0.025 & -0.178 & -0.192 \\
\hline \hline
\end{tabular}

The table shows the estimates for a linear regression model of authoritative parental investments on current period child's skills and peer's skills with breakdown by (authoritarian) parenting style. Odd columns display the estimates generated from the simulated model. Even columns show the estimates from the data. We calculate the model's predicted coefficients by averaging among 50 different model simulations. 


\section{B Measuring Skills and Parental Investments in Add Health}

In this section we provide additional details on how we measure children's skills and parental investment in Add Health.

Parenting Style. We measure parenting style using the following yes-no question asked to children during the in-home survey: "Do your parents let you make your own decisions about the people you hang around with?" We classify a parent whose child answers "No" as adopting an authoritarian parenting style.

Other Parental Investments (Time). We measure parental investments using the following yes-no questions asked to children during the in-home survey about certain activities they engaged in with their mothers: "Talked with your mom about a party you attended"; "Talked with your mom about a personal problem"; "Worked with your mom on a project for school."We aggregate the three measures using a principal component analysis.

Children's Skills: We measure children's skills using both grades at school (English, Math, History and Science) and a standardized test of receptive vocabulary (Peabody Picture Vocabulary Test, PPVT). ${ }^{33}$ Similar to Cunha and Heckman (2007), Cunha, Heckman, and Schennach (2010), Agostinelli and Wiswall (2016), Attanasio, Meghir, and Nix (2019), and Attanasio et al. (2020), we use a linear measurement system to have a comparable scaling between different measures. The measurement model maps each of the five observed measures above $\left(M_{i, t}^{m}\right)$ into children's skills $\left(\theta_{i, t}\right)$ as follows:

$$
M_{i, t}^{m}=\nu_{0, m}+\nu_{1, m} \ln \theta_{i, t}+\eta_{i, t}^{m} .
$$

This model allows us to have a linear transformation for each measure $m$ that measures the children's skills: $\widetilde{M}_{i, t}^{m} \equiv \frac{M_{i, t}^{m}-\nu_{0, m}}{\nu_{1, m}}=\ln \theta_{i, t}+\widetilde{\eta}_{i, t}^{m} \cdot{ }^{34}$ Once we have the set of re-scaled measures $\left\{\widetilde{M}_{i, t}^{m}\right\}_{m=1}^{5}$, we aggregate them using a principal component analysis to deal with the measurement error $(\eta)$. The estimates of the measurement parameters in Equation (B-1) are shown below:

\footnotetext{
${ }^{33}$ Add Health includes the PPVT scores only for Wave I.

${ }^{34}$ The re-scaled measurement error is $\widetilde{\eta}_{i, t}^{m}=\frac{\eta_{i, t}^{m}}{\nu_{1, m}}$.
} 
Table B-1: Estimates for the Measurement Model in (B-1)

\begin{tabular}{lcc} 
& $\nu_{0}$ & $\nu_{1}$ \\
\cline { 2 - 3 } English Grade & 2.55 & 0.76 \\
Math Grade & 2.48 & 0.55 \\
Math Grade & 2.60 & 0.82 \\
History Grade & 2.51 & 0.76 \\
PPVT & 60.53 & 2.65 \\
\hline
\end{tabular}

The table shows the estimates for the measurement model in Equation (B-1). The parameter are estimated under a zero mean and unitary variance normalization of the log-skills in 9th grade (see Cunha and Heckman (2007), Cunha, Heckman, and Schennach (2010), and Agostinelli and Wiswall (2016) for further details). 


\section{Robustness Analysis}

\section{C.1 Additional Specifications for the Technology of Skill Formation}

Tables C1-1 through C1-3 provide the results for a set of robustness analyses. In all the different exercises we use the same estimator as in our baseline estimation algorithm (Simulated Method of Moments). We describe each case below.

General CES Technology for Both Parenting Styles. In this first robustness exercise we specify a different unconstrained CES technology for each parenting style (authoritarian and nonauthoritarian parents). Because the model is already overidentified, we do not add additional statistics to our set of moments to match. Moreover, we already included key identifying information as we already allowed the auxiliary regressions about next-period skills to differ between authoritarian and nonauthoritarian parents (see Table A-4). Table C1-1 shows the estimates for the new technological parameters. The estimated complementary parameter for authoritarian parents is close to zero, suggesting that the technology in this case is effectively Cobb-Douglas. The rest of the parameters are in line with our baseline estimates (see Table 5). ${ }^{35}$

Restricted CES Technology. In this case we impose various restrictions on how the technology of skill formation varies between authoritarian and nonauthoritarian parents. In the first case, we impose that authoritarian and nonauthoritarian parents share the same technology of skill formation (CES), although we still allow parenting style to affect the technological TFP. We estimate the specification of this new model. Table C1-2 shows the results for the estimated technology. We estimate a lower effect of parenting style on the technological TFP $\left(\psi_{2}\right)$ relative to our baseline estimates. However, the specification is not able to replicate the heterogeneity of the elasticity of parental investments with respect to peers' skills between authoritarian and nonauthoritarian parents (previously reported in Table A-6). In the second case, we restrict the TFP to also be invariant to parenting style on top of the same technological restrictions described above. The results are shown in Table C1-3. Even in this case, this specification is not able to repli-

\footnotetext{
${ }^{35}$ In Section 4.1 we discuss how to compare the parameters between the CES and the CobbDouglas case.
} 
cate the heterogeneous responses of parental investments with respect to changes in peer quality between authoritarian and nonauthoritarian parents.

Taken together, these robustness checks suggest that allowing the technology of skill formation to vary between authoritarian and nonauthoritarian parents is essential for getting a good model fit and that imposing a Cobb-Douglas specification for authoritarian parents fits the data well.

Table C1-1: Estimates for the Technology of Skills Formation (General Two CES Case)

\begin{tabular}{lc}
\hline \hline & CES (Authoritarian =1) \\
\cline { 2 - 2 } Complementarity Parents vs. Peer $\left(\alpha_{4,0}\right)$ & 0.009 \\
Share Self-Production $\left(\alpha_{1,0}\right)$ & 0.772 \\
Share Peer Skills $\left(\alpha_{2,0}\right)$ & 0.382 \\
Complementarity Self-Production vs. Parents-Peer $\left(\alpha_{3,0}\right)$ & 0.009 \\
CES Return to Scale $\left(\alpha_{5,0}\right)$ & 0.502 \\
& CES (Authoritarian $=0)$ \\
\cline { 2 - 2 } Complementarity Parents vs. Peer $\left(\alpha_{4,1}\right)$ & 0.789 \\
Share Self-Production $\left(\alpha_{1,1}\right)$ & 0.565 \\
Share Peer Skills $\left(\alpha_{2,1}\right)$ & 0.381 \\
Complementarity Self-Production vs. Parents-Peer $\left(\alpha_{3,1}\right)$ & -1.613 \\
CES Return to Scale $\left(\alpha_{5,1}\right)$ & 1.103 \\
TFP Constant $\left(\psi_{0}\right)$ & Total Factor Productivity \\
\cline { 2 - 2 } TFP Age Trend $\left(\psi_{1}\right)$ & 0.393 \\
TFP Parenting Style $\left(\psi_{2}\right)$ & 0.024 \\
\hline \hline
\end{tabular}

The table shows the estimates for the technology of skill formation for the general model with two CES production functions. 
Table C1-2: Estimates for the Technology of Skills Formation (One Technology for All Parents)

\begin{tabular}{lc}
\hline \hline & CES (For All Parents) \\
\cline { 2 - 2 } Complementarity Parents vs. Peers $\left(\alpha_{4,0}\right)$ & 0.808 \\
Share Self-Production $\left(\alpha_{1,0}\right)$ & 0.558 \\
Share Peer Skills $\left(\alpha_{2,0}\right)$ & 0.393 \\
Complementarity Self-Production vs. Parents-Peers $\left(\alpha_{3,0}\right)$ & -1.766 \\
CES Return to Scale $\left(\alpha_{5,0}\right)$ & 0.954 \\
& Total Factor Productivity \\
\cline { 2 - 2 } TFP Constant $\left(\psi_{0}\right)$ & 0.427 \\
TFP Age Trend $\left(\psi_{1}\right)$ & 0.028 \\
TFP Parenting Style $\left(\psi_{2}\right)$ & -0.026 \\
\hline \hline
\end{tabular}

The table shows the estimates for the technology of skill formation. In this case, we assume one technology for all parents.

Table C1-3: Estimates for the Technology of Skills Formation (One Technology for All Parents with same TFP)

\begin{tabular}{lc}
\hline \hline & CES (For All Parents) \\
\cline { 2 - 2 } Complementarity Parents vs. Peers $\left(\alpha_{4,0}\right)$ & 0.817 \\
Share Self-Production $\left(\alpha_{1,0}\right)$ & 0.564 \\
Share Peer Skills $\left(\alpha_{2,0}\right)$ & 0.397 \\
Complementarity Self-Production vs. Parents-Peers $\left(\alpha_{3,0}\right)$ & -1.755 \\
CES Return to Scale $\left(\alpha_{5,0}\right)$ & 0.947 \\
& Total Factor Productivity \\
\cline { 2 - 2 } TFP Constant $\left(\psi_{0}\right)$ & 0.423 \\
TFP Age Trend $\left(\psi_{1}\right)$ & 0.027 \\
\hline \hline
\end{tabular}

The table shows the estimates for the technology of skill formation. In this case, we assume one technology for all parents with the same TFP term. 


\section{C.2 Model with Parental Education}

In this section we generalize our model by including heterogeneous parents with respect to their education. In particular, we divide parents into low- and highly educated parents $\left(E_{i} \in\{0,1\}\right)$, depending on whether they attained a college degree. We allow parental education to affect both technology and preferences: highly educated parents have a differential TFP term as well as a different parameter for the disutility of engaging in an authoritarian parenting style.

The new technology of skill formation is defined as follows:

$$
s\left(\theta_{i, t}, \bar{\theta}_{i, t}, I_{i, t}, P_{i, t}=p\right)=A_{p}(t) \times H_{p}\left(\theta_{i, t}, \bar{\theta}_{i, t}, I_{i, t}\right),
$$

where $p \in\{0,1\}, A_{p}(t)=\exp \left(\psi_{0,1}+\psi_{0,2} \cdot E_{i}+\psi_{1} \cdot t+\psi_{2} \cdot p\right)$, where $\psi_{0,2}$ represents the additional TFP for highly educated parents $\left(E_{i}=1\right)$. A positive value for $\psi_{0,2}$ means that highly educated parents have higher total factor productivity relative to low-educated parents. The rest of the technological parameters are the same as in Equation (7).

Low- and highly educated parents differ in their disutility of being authoritarian. We model the new parents' preferences as follows:

$$
U\left(I_{i, t}, P_{i, t}, \epsilon_{i, t}\right)=\delta_{1} \ln \left(1-I_{i, t}\right)+\delta_{2,1}\left(1+\delta_{2,2} \cdot E_{i}\right) P_{i, t}+\epsilon_{i, t}\left(P_{i, t}\right),
$$

where the parameter $\delta_{2,2}$ captures the differential cost of engaging in an authoritarian parenting style. A negative value for $\delta_{2,2}$ means that highly educated parents are less prone to be authoritarian relative to low-educated parents.

The model is estimated using the Simulated Method of Moments (SMM), where we add to the previous set of moments two additional statistics to match: 1) the auxiliary coefficient of the marginal effect of parental education on the probability of becoming authoritarian, and 2) the auxiliary coefficient of the marginal effect of parental education on the next-period skills. ${ }^{36}$

Table C2-1 shows the estimates for the new parameters. The results suggest

\footnotetext{
${ }^{36}$ In Add Health we measure parental education based on the mother's reported highest grade concluded.
} 
that TFP differences between parents are minimal, while highly educated parents show a 25 percent higher disutility in becoming authoritarian relative to low-educated parents. The rest of the estimated parameters are unchanged with respect to our previous estimates.

Table C2-1: Estimates for Heterogeneous TFP and Preferences by Education

Technology:

$\begin{array}{ll}\text { TFP Contant }\left(\psi_{0,1}\right) & 0.412\end{array}$

$\begin{array}{ll}\text { Additional TFP (highly educated parents, } \psi_{0,2} \text { ) } & 0.012\end{array}$

Preferences:

Disutility of Authoritarian $\left(\delta_{2,1}\right) \quad-2.110$

Additional Disutility of Authoritarian (highly educated parents, $\delta_{2,2}$ ) $\quad-0.510$

The table shows the main estimates for the TFP technology and preferences for a model with heterogeneous parents (education). In this case, parents are heterogeneous with respect to their education (college graduates versus non-college graduates). The table shows the estimated parameters. The rest of the model's parameters are assumed homogeneous, and they are omitted from the table because they are in line with the previous estimates. Results are available upon request. 